\title{
WestVirginiaUniversity
}

THE RESEARCH REPOSITORY @ WVU

Graduate Theses, Dissertations, and Problem Reports

2016

\section{Elucidating Mechanisms of Canonical Wnt - ephrin-B Crosstalk}

William Tyler Koch

Follow this and additional works at: https://researchrepository.wvu.edu/etd

\section{Recommended Citation}

Koch, William Tyler, "Elucidating Mechanisms of Canonical Wnt - ephrin-B Crosstalk" (2016). Graduate Theses, Dissertations, and Problem Reports. 5996.

https://researchrepository.wvu.edu/etd/5996

This Thesis is protected by copyright and/or related rights. It has been brought to you by the The Research Repository @ WVU with permission from the rights-holder(s). You are free to use this Thesis in any way that is permitted by the copyright and related rights legislation that applies to your use. For other uses you must obtain permission from the rights-holder(s) directly, unless additional rights are indicated by a Creative Commons license in the record and/ or on the work itself. This Thesis has been accepted for inclusion in WVU Graduate Theses, Dissertations, and Problem Reports collection by an authorized administrator of The Research Repository @ WVU. For more information, please contact researchrepository@mail.wvu.edu. 


\title{
Elucidating Mechanisms of Canonical Wnt - ephrin-B Crosstalk
}

\section{William Tyler Koch}

\author{
Thesis submitted \\ to the Eberly College of Arts and Sciences \\ at West Virginia University
}

in partial fulfillment of the requirements for the degree of

Master of Science in

Cell, Molecular, and Developmental Biology

Shuo Wei, Ph.D., Chair

Ashok Bidwai, Ph.D.

Clif Bishop, Ph.D.

Department of Biology

Morgantown, West Virginia

2016

Keywords: Biology, Cell Signaling, Development, Cancer, Colorectal Cancer, Wnt, $\beta$-catenin, Wnt/ $\beta$-catenin, Eph, ephrin, Eph/ephrin, E-cadherin, HEK293T, TOPIFOP FLASH, Luciferase Assay, Western Blot, Confocal, Immunofluorescence

Copyright @ 2016 William Tyler Koch 


\section{ABSTRACT}

\section{Elucidating Mechanisms of Canonical Wnt - ephrin-B Crosstalk}

\section{William Tyler Koch}

Throughout development, canonical Wnt signaling contributes to the formation and maintenance of a wide array of cells, tissues, and organs. Dys-regulated Wnt signaling during embryonic development is implicated in developmental defects known as neurochristopathies, including craniofacial and heart defects, as well as defects in neural development. Due to its roles in stem cell maintenance and self-renewal, tissue homeostasis, and regeneration, aberrant Wnt signaling in adult tissues can result in various forms of cancer, including colorectal cancer, breast cancer, lung cancer, and gastro-intestinal cancer, among others. Dys-regulated Wnt signaling is also implicated in other pathologies including bone disease, and metabolic diseases, such as Type II diabetes. Our lab has previously identified a novel crosstalk between canonical Wnt signaling and ephrin signaling. Ephrin signaling occurs through the interaction of ephrin ligands and Eph receptor tyrosine kinases, and is bidirectional. Due to the roles of ephrin signaling in tissue development and maintenance, aberrant ephrin signaling is implicated in many diseases including bone remodeling diseases, diabetes, and cancer. The molecular mechanism of the crosstalk between canonical Wnt signaling and ephrin$B$ signaling remains unknown. $\beta$-catenin is a key intracellular effector of canonical Wnt signaling that transduces the signal to the nucleus, where $\beta$-catenin interacts with the TCF/LEF transcription factors and activates transcription of target genes. Due to its central role in transducing the canonical Wnt signal to the nucleus, we predict that ephrin-B signaling antagonizes canonical Wnt signaling by affecting the stability and/or sub-cellular localization of $\beta$-catenin, or the interaction between $\beta$-catenin and TCF/LEF transcription factors. By employing mouse ephrin-B constructs in human cell lines, we show that the canonical Wnt - ephrin-B crosstalk is conserved between frogs and mammals. We also found that ephrin-B antagonism of canonical Wnt signaling is likely independent of ubiquitin proteasome system (UPS)-mediated degradation of $\beta$-catenin. Furthermore, confocal immunofluorescence microscopy revealed that overexpression of ephrin-B in HEK293T cells treated with lithium chloride ( $\mathrm{LiCl}$ ) seems to promote membrane localization of $\beta$-catenin, particularly at the apical $Z$ sections. These results suggests that re-localization of $\beta$-catenin to the cell membrane may contribute to the ephrin-B antagonism of canonical Wnt signaling. 
We stare straight into nothing But we call it all the same

- Adam Granduciel 


\section{Acknowledgements}

There are so many people to thank, but only so many words to express my gratitude for all of their support. I believe in humanity, and these humans and their

humanity made my personal growth possible.

I would like to thank my advisor, Dr. Shuo Wei, for providing this opportunity, sharing his knowledge, and supporting me in this work. I learned so much just by being in your presence and working alongside you, watching and listening to you evaluate evidence and plot out next steps. You always challenged me to be my best, and I failed to see that in certain moments. I am so grateful for all of the support you gave me: I owe you some pie and coffee!

I would like to thank the advisor of my undergraduate research at James Madison University, Dr. Chris Rose, for inspiring me to pursue research in cell and developmental biology and nurturing my passion at a critical time. You shared your

confidence in my ability when others had doubted my academic potential and encouraged me to pursue my passion for biology and research.

I would like to thank the members of my graduate committee, Dr. Ashok Bidwai and Dr. Clif Bishop for their advice and support of this thesis. Dr. Bidwai, you always knew how to calm my nerves and get me to relax. Dr. Bishop, your stories were always entertaining and a great distraction from our serious work.

I would like to thank the past and present members of Dr. Wei's Lab. Dr. Harinathichai Bhahudhanapati, your kindness and patience are transcendent, and rivaled only by your love of movies and 24-hour TV news. Dr. Laura Christian, you taught me all the techniques I needed to perform this research, and you will always be a nerdier nerd than me. Dr. Jeijing Li, you helped me solve one of the biggest mysteries

in this thesis; some PBS dried onto my microscope slides. Your positive nature and humor are infectious. Mark Perfetto (Ph.D. candidate), you were always open to spitball ideas, and I could always confide in you. Your passion for knowledge is matched

only by your sarcasm. Shashwati Bhattacharya, M.S., you always knew how to convince me that everything would work out in the end.

I would like to thank the undergraduate researchers, Carlos Nathan and Crestyn White. You guys are outstanding, and I learned so much from sharing knowledge with you.

I would like to thank West Virginia University and the Department of Biology.

Finally, I would like to thank my family and friends without whom I would be completely lost. 


\section{Table of Contents}

Chapter 1: Introduction.

p.1-28

\section{1: Canonical Wnt Signaling}

1.1.1: Canonical Wnt Signaling p.1

1.1.2: Dual Roles of $\beta$-catenin: $\beta$-catenin Structure and Function p.3

1.1.3: Regulation of $\beta$-catenin Stability. p.6

1.1.4: $\beta$-catenin Subcellular Localization p.10

1.2: Ephrin Signaling

1.2.1: Ephrin Signaling p.12

1.3: Canonical Wnt - ephrin-B Crosstalk

1.3.1: Evidence of Canonical Wnt - ephrin-B Crosstalk. p.21

1.3.2: Regulators of $\beta$-catenin Stability and Localization p.26

1.3.3: c-Jun $\mathrm{N}$-terminal kinase 1 and 2 (JNK1, JNK2) p.26

\section{Chapter 2: Specific Aims} p.29-31

2.1: Specific Aims p.29

2.2: Specific Aims Approaches p.30

Chapter 3: Methods p.32-34

Chapter 4: Results. p.35-52

Chapter 5: Discussion p.53-55 Chapter 6: Works Cited. p.56-66 


\section{List of Figures}

Figure 1: $\beta$-catenin ARM Domain Interactors …............................................... p.5

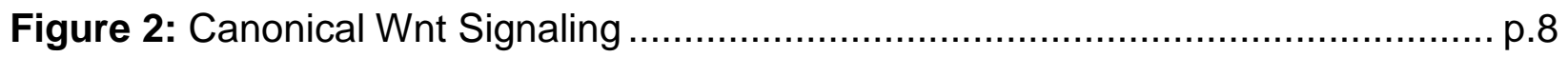

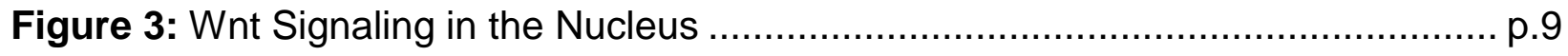

Figure 4: Eph/ephrin Domain Organization and Signaling Modes ......................... p.16

Figure 5: Eph/ephrin Complexes and Receptor Clustering, and Downstream Molecular Pathways and Cellular Responses ................... p.19

Figure 6: Canonical Wnt and Eph/ephrin Interactions in the Intestinal Stem Cell Niche and Colorectal Cancer Progression................ p.23

Figure 7: Wild-type ephrin-B and ephrin-B1 $\Delta \mathrm{C}$ Inhibit Wnt3a - Induced

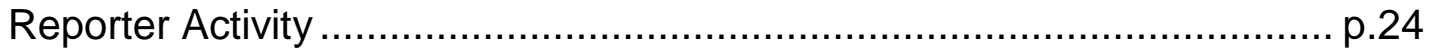

Figure 8: Regulation of the Wnt Signaling Axis ................................................ p.25

Figure 9: Ephrin-B Signaling Activates c-Jun N-terminal kinase (JNK) …............. p.27

Figure 10: Proposed Models for JNK-mediated ephrin-B Antagonism

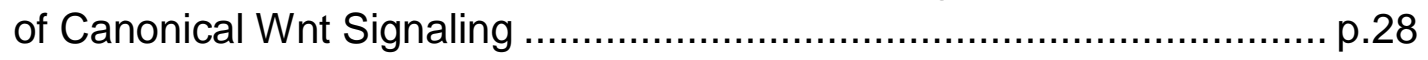

Figure 11: Wnt3a Overexpression is Not Sufficient to Induce Reporter Activity ........ p.37

Figure 12: Wnt8 Overexpression is Not Sufficient to Induce Reporter Activity ......... p.38

Figure 13: Wild-type $\beta$-catenin Overexpression Induces Reporter Activity............... p.39

Figure 14: ephrin-B1 $\Delta C$ Inhibits Wild-type $\beta$-catenin - Induced Reporter Activity..... p.40

Figure 15: LiCl Induces Reporter Activity ....................................................... p.41

Figure 16: ephrin-B1 $\Delta \mathrm{C}$ Inhibits LiCl - Induced Reporter Activity .......................... p.42

Figure 17: $\beta$-catenin* Overexpression Induces Reporter Activity …....................... p.43

Figure 18: ephrin-B1 $\Delta C$ Inhibits $\beta$-catenin* - Induced Reporter Activity .................. p.44

Figure 19: ephrin-B Signaling Affects Levels of Total Cellular $\beta$-catenin .................. p.45

Figure 20: ephrin-B Signaling Affects Levels of Total Cellular $\beta$-catenin ................. p.46

Figure 21: LiCl and ephrin-B Signaling Increase Levels of Total Cellular E-cadherin Independently and Co-Treatment Does Not Influence this Effect. 


\section{List of Figures}

Figure 22: Subcellular Localization of $\beta$-catenin in Response to ephrin-B Signaling in Apical, Middle, and Basal Z Sections

Figure 23: Subcellular Localization of $\beta$-catenin in Response to ephrin-B Signaling in Apical Z Sections........................................... p.49

Figure 24: Subcellular Localization of $\beta$-catenin in Response to ephrin-B Signaling in Middle Z Sections........................................... p.50

Figure 25: Subcellular Localization of $\beta$-catenin in Response to ephrin-B Signaling in Basal Z Sections ............................................. p. 51

Figure 26: Inhibition of C-Jun N-terminal kinase (JNK) Inhibits

$\mathrm{LiCl}$ - Induced Reporter Activity and Enhances the ephrin-B1 $\Delta \mathrm{C}$ Inhibition of LiCl - Induced Reporter Activity 


\section{Chapter 1: Introduction}

\section{1: Canonical Wnt Signaling}

\subsection{1: Canonical Wnt Signaling}

There are 19 identified mammalian Wnt homologs, which include 22 cysteine residues whose spacing and arrangement is highly conserved, a signal sequence for secretion, and potential glycosylation sites (Kikuchi, 2011; Mikels, 2006). Wnt ligands do not function as a classical morphogen by establishing a chemical gradient, but instead mediate close range signaling between cells that are close to one another (Clevers, 2012). Wnt ligands are palmitoylated in the endoplasmic reticulum (ER) by the Porcupine (Porc) enzyme, and are glycosylated to ensure proper secretion (Takada, 2006; Lorenowicz, 2009; Port, 2010; Herr, 2012; Clevers, 2012). Palmitoylated Wnt ligands are transported to the Golgi network where they bind to the Evi/Wntless multi-pass transmembrane protein (Takada, 2006; Lorenowicz, 2009; Port, 2010; Herr, 2012; Clevers, 2012). The Wnt/Evi/Wntless complexes are secreted from the Golgi network in endosomal vesicles, which transport Wnt ligands to the plasma membrane to be secreted from the cell (Takada, 2006; Lorenowicz, 2009; Port, 2010; Herr, 2012; Clevers, 2012). Wnt ligands were first found to bind the cysteine rich domain (CRD) of Frizzled (Fz), a 7-transmembrane protein of the GPCR family (Bhanot, 1996). The palmitoleic acid group extends from the "thumb" region of the Wnt ligand into the cysteine rich domain (CRD) of Fz, reinforcing the Wnt-Fz interaction (Takada, 2006; Lorenowicz, 2009; Port, 2010; Herr, 2012; Clevers, 2012). A single Wnt can bind multiple Fz receptors and a single Fz receptor can also bind multiple Wnt ligands (Bhanot, 1996). Upon binding of Wnt ligand, Fz forms receptor complexes with co-receptors, including low-density lipoprotein receptor-related proteins 5/6 (LRP5/6), receptor Tyr kinase-like orphan receptors 1/2 (Ror1/2), and protein Tyr kinase 7 (PTK7) ${ }^{(L i, ~ 2005 ; ~ G r u m o l a t o, ~ 2010 ; ~ P e r a d z i r y i, ~ 2012) . ~}$

Wnt ligands also bind various agonists, such as the R-spondin family and Norrin, and antagonists, such as Cerberus, Dickopf-related protein 1 (DKK1), secreted Frizzledrelated protein (SFRP), Wnt inhibitory factor (WIF), Sclerostin (and its homologue Wise), which regulate Wnt signaling by affecting the assembly of ligand - receptor complexes and/or the recruitment of co-receptors, or by affecting receptor endocytosis 
(Cruciat, 2012; Niehrs, 2012). Furthermore, Wnt ligands have since been found to also bind alternate receptors independently of Fz through their interaction with a CRD and/or a Wnt inhibitory factor (WIF) domain (Mikels, 2006). In this manner, Wnt ligands were found to bind the CRDs of Ror and the muscle skeletal receptor Tyr kinase (MUSK), as well as the WIF domain of the cell surface atypical receptor tyrosine kinase, receptor Tyr kinase (Ryk). These receptors may function as alternate receptors and/or Fz coreceptors ${ }^{(\text {Mikels, 2006) }}$. Specific combinations of Wnt ligands, receptors, co-receptors, and cellular context induce various downstream signaling events which induce different cellular responses. Depending on the induced downstream signaling events and the cellular responses elicited, Wnt signaling is defined as either canonical or noncanonical. Generally speaking, canonical Wnt signaling involves binding of Wnt ligands to Fz/LRP5/6, resulting in the stabilization and nuclear localization of the intracellular effector, $\beta$-catenin, which in turn binds to T-cell/lymphoid enhancer factor (TCF/LEF) transcription factors and activates transcription of canonical Wnt target genes. Noncanonical Wnt signaling, however, involves Wnt5a, Wnt11, or other Wnt ligands binding to alternate Wnt receptors, such as Ryk, Ror, and MUSK, or to Fz, which recruits alternate co-receptors, ultimately resulting in activation of distinct downstream intracellular signaling events which may not involve stabilization and nuclear localization of $\beta$-catenin. Accordingly, canonical Wnt signaling is commonly referred to as $\beta$-catenin dependent Wnt signaling, while non-canonical Wnt signaling is commonly referred to as $\beta$-catenin independent Wnt signaling. Canonical Wnt signaling will be our focus heretofore.

Canonical Wnt signaling is activated during embryonic development, as well as in proliferating, migrating, and differentiating cells in adult tissues (Teo, 2010; Schambony, 2013; Aman, 2008). Canonical Wht signaling plays key roles in embryonic development, contributing to processes of axis patterning, cell fate specification, cell polarity, cell proliferation, and cell migration (Peterson, 2009; Hikasa, 2013; Clevers, 2006a; van Amerongen, 2009). Canonical Wnt is involved in gastrulation and body axis formation, including specification of anteroposterior and dorsoventral axes (van Amerongen, 2009; Hikasa, 2013; Peterson, 2009). Canonical Wnt signaling induces mesoderm and endoderm during embryonic development, and contributes to hematopoiesis (Clevers, 2006a). At later stages, canonical 
Wnt signaling also contributes to the formation and maintenance of cartilage and bone, heart, muscle, neurons of the peripheral and central nervous systems, skin, blood cells, and other tissues (Regard, 2012; Baron, 2013; Buikema, 2014; von Maltzahn, 2012; Patthey, 2008; Salinas, 2012; Lim, 2013; Lento, 2013). One example of the function of canonical Wnt signaling in development is its involvement in the induction of neural crest cells, which migrate throughout the embryo and differentiate, contributing to multiple tissues and organs including the peripheral nervous system, the heart, and craniofacial bone and cartilage (Elkouby, 2010; Wu, 2005; Le Douarin,1999). Dys-regulated Wnt signaling affects neural crest cell development, and is implicated in developmental defects known as neurochristopathies, including craniofacial and heart defects, as well as defects in neural development (Etchevers, 2006; Alexander, 2014; Veerle, 2008; Patthey, 2008)

Canonical Wnt signaling is also involved in stem cell maintenance and selfrenewal, tissue homeostasis, regeneration, and regulates insulin sensitivity in cells (Clevers, 2014; Clevers, 2012; Palsgaard, 2012; Abiola, 2009). A Aberrant Wnt signaling can result in various forms of cancer, including colorectal cancer, gastrointestinal cancer, breast cancer, lung cancer, glioblastoma, leukemia, melanoma, among others (Clevers, 2012; Giles, 2003; Morin, 1997; Logan, 2004; Reya, 2005; Bienz, 2000; de Lau, 2007; Schepers, 2012; Howe, 2004; Nguyen, 2009; Rheinbay, 2013; Damsky, 2011). Aberrant Wnt signaling contributes to oncogenesis by promoting tumor cell proliferation and metastasis (Polakis, 2012; Clevers, 2012; Reya, 2005; Nguyen, 2009). Canonical Wnt mutations that result in these cancers include mutations to $\beta$-catenin, mutations to APC and other components of the $\beta$-catenin destruction complex, overexpression of Wnt ligands, loss of inhibitors, and decreased activity of other signaling pathways that regulate canonical Wnt signaling (Morin, 1997; Polakis, 2012; Clevers, 2012; Reya, 2005; Logan, 2004). In addition to developmental defects and its roles in carcinogenesis, dys-regulated Wnt signaling is implicated in other pathologies including bone disease, and metabolic diseases, such as Type II diabetes ${ }^{(B a r o n, 2013 ;}$ Herr, 2012; Clevers, 2012).

\subsection{2: Dual Roles of $\beta$-catenin: $\beta$-catenin Structure and Function}

$\beta$-catenin is a key intracellular effector of canonical Wnt signaling that transduces the signal to the nucleus, where $\beta$-catenin interacts with the TCF/LEF transcription factors and activates transcription of Wnt/ $\beta$-catenin target genes (Cadigan, 2012). However, 
non-canonical Wnt signaling, as mentioned earlier, is independent of $\beta$-catenin (van Amerongen, 2012). In addition to its role in signaling, $\beta$-catenin plays a critical role in stabilizing cell-cell adherens junctions by interacting with classical cadherins such as Ecadherin, a transmembrane protein, and linking it to cytoskeletal structures (Conacci-Sorrell, 2003). The recruitment and retention of $\beta$-catenin at adherens junctions through its binding to the cytoplasmic tail of E-cadherin result in a pool of intracellular, membranebound $\beta$-catenin in the cell. Along with the negative regulatory activity of the $\beta$-catenin destruction complex, a micro-environment that is restrictive of canonical Wnt signaling emerges in cells participating in many cell-cell interactions and free of Wnt ligand stimulation (i.e. cells that form tissues in vivo, and dense culture conditions in vitro). This phenomenon results in a decrease in nuclear $\beta$-catenin levels and Wnt signaling activation (Conacci-Sorrell, 2003). Due to this phenomenon, dense cell cultures have lower nuclear $\beta$-catenin and Wnt signaling activation than sparse cell cultures (Conacci-Sorrell, 2003). The ability of $\beta$-catenin to participate in these diverse activities within the cell is elucidated by its structure.

$\beta$-catenin, a member of armadillo multigene family, is a $90 \mathrm{kDa}$ protein, and is 781 amino acids long (in humans), consisting of flexible N-terminal and C-terminal domains (NTD, CTD) flanking a rigid central region made up of 12 Armadillo repeats (Valenta, 2012). The CTD is linked to the central region by a conserved helix, Helix-C (Xing, 2008). The various interaction partners of $\beta$-catenin bind to the long, positively charged groove of the Armadillo repeats by forming salt bridges with Lys312 and Lys435 (Valenta, 2012). Only one of these interaction partners, including E-cadherin, adenoma polyposis coli (APC), and TCF/LEF, can bind to $\beta$-catenin at a time, creating competition for $\beta$ catenin and regulating the function of $\beta$-catenin based on its availability and subcellular localization (Figure 1) (Krieghoff, 2006; Valenta, 2012; Morgan, 2014). Accordingly, maintenance of different pools of $\beta$-catenin within the cell and post-translational modifications control the spatial separation, retention, and stability of $\beta$-catenin, contributing to its dual role as a signaling molecule and structural protein (Valenta, 2012; Morgan, 2014). 


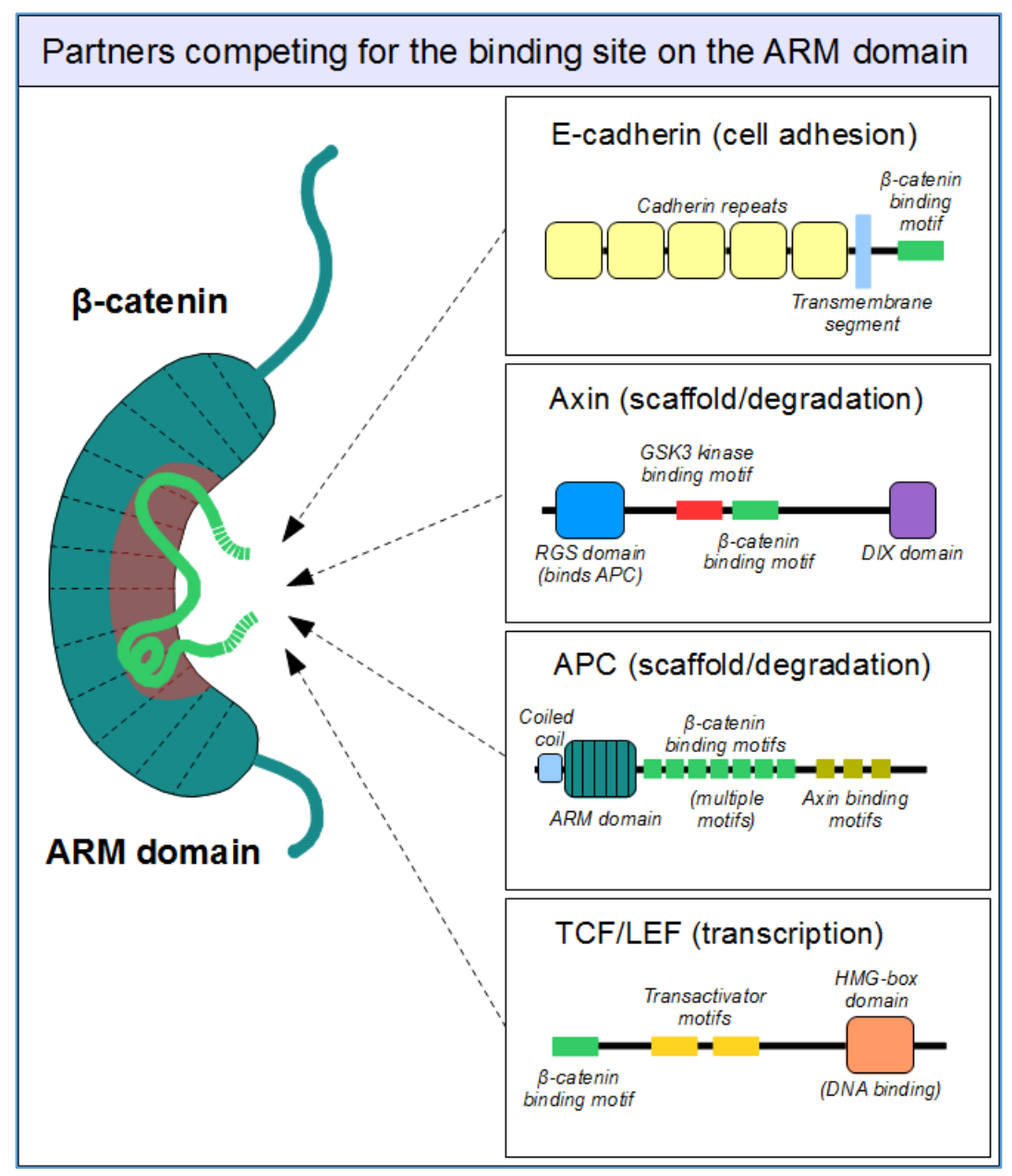

Figure 1: $\beta$-catenin ARM Domain Interactors. E-cadherin, Axin, APC, and the TCF/LEF transcription factors are known to interact with the ARM domain of $\beta$-catenin. Only one of these interaction partners, including E-cadherin, adenoma polyposis coli (APC), and TCF/LEF, can bind to $\beta$-catenin at a time, creating competition for $\beta$-catenin and regulating the function of $\beta$-catenin based on its availability and subcellular localization (Image reprinted with permission from Creative Commons: Image by Bubus12 (Own work) [CC BY 3.0 license], via Wikimedia Commons). 


\subsection{3: Regulation of $\beta$-catenin Stability}

The balance between sequestration of $\beta$-catenin by cadherins at adherens junctions and canonical Wnt signaling activity affects the levels of cytoplasmic $\beta$-catenin (Conacci-Sorrell, 2003; Valenta, 2012). In the absence of Wnt signaling, cytoplasmic $\beta$-catenin is phosphorylated and ubiquitinated, marking it for degradation via the $26 \mathrm{~S}$ proteasome by a multi-protein destruction complex that resides in the cytoplasm known as the $\beta$ catenin destruction complex. The $\beta$-catenin destruction complex, hereafter referred to solely as the destruction complex, consists of Dishevlled (Dvl), the scaffold proteins Axin and APC, the kinases glycogen synthase kinase $3 \beta$ (GSK3 $\beta$ ) and casein kinase 1 $\alpha(C K 1 \alpha)$, the phosphatase protein phosphatase 2A (PP2A), and the E3 ubiquitin ligase F-box protein $\beta$-transducin repeat containing protein ( $\beta$-TrCP) ${ }^{(L i, 2012 b ; ~ S t a m o s, ~ 2013 ; ~ V a l e n t a, ~}$ 2012; Clevers, 2012). Cytoplasmic $\beta$-catenin binds to APC and Axin, which recruit $\beta$-catenin to the destruction complex (Li 2012; Clevers, 2012; Stamos 2013). These interactions bring $\beta$-catenin in close proximity of CK1 $\alpha$ and GSK3 $\beta$, allowing their sequential phosphorylation of $\beta$ catenin (Liu 2002; Zeng, 2005; Verheyen, 2010). CK1 $\alpha$ phosphorylates $\beta$-catenin at Ser45, which primes $\beta$-catenin for the subsequent sequential phosphorylation of Thr41, Ser37, and Ser33 by GSK3 $\beta$ (Liu 2002; Zeng, 2005; Verheyen, 2010). Phosphorylation of $\beta$-catenin by GSK3 $\beta$ is dependent upon interaction of GSK3 $\beta$ with Axin and APC (Valenta, 2012). These phosphorylation events result in the formation of the DSGXXS degron motif at the $\mathrm{N}$ terminal domain of $\beta$-catenin, which is recognized by the $F$-box protein $\beta$-transducin repeat containing protein ( $\beta$-TrCP) (Lau, 2012; Clevers, 2012; valenta, 2012). APC protects the phosphorylated DSGXXS degron from dephosphorylation by PP2A ${ }^{(\mathrm{Su}, 2008)}{ }^{\text {. Binding of }}$ $\beta$-TrCP associates $\beta$-catenin with the E3 ubiquitin ligase complex, Skp1/Cul1/F-box/ $\beta$ $\operatorname{TrCP}\left(\right.$ SCF ${ }^{\beta-T r C P}$ ), resulting in the ubiquitination of $\beta$-catenin and its subsequent degradation by the $26 \mathrm{~S}$ proteasome (Hart, 1999; Latres,1999; Li 2012; Stamos 2013; Valenta, 2012). The degradation of cytoplasmic $\beta$-catenin by the destruction complex prevents cytoplasmic accumulation of $\beta$-catenin, thereby preventing the translocation of $\beta$-catenin to the nucleus and the initiation of transcription of Wnt target genes (Li, 2012b; Clevers, 2012; Stamos, 2013; Valenta, 2012). In addition to degradation of cytoplasmic $\beta$-catenin, transcription of $\mathrm{Wnt} / \beta$-catenin target genes are further repressed by epigenetic events in the absence of Wnt signaling. The co-repressor Groucho binds to TCF/LEF transcription factors in the 
absence of Wnt signaling, and along with other epigenetic factors, inhibits the transcription of Wht target genes (Roose, 1998; Daniels, 2005; Clevers, 2012; Valenta, 2012).

Binding of Wnt ligands to $\mathrm{Fz}$ and LRP5/6 results in inhibition of the $\beta$-catenin destruction complex (Valenta, 2012). In the presence of canonical Wnt ligand, Fz and LRP5/6 form a heterodimeric receptor complex (Valenta, 2012; Clevers, 2012). The cytoplasmic tail of Fz interacts with DVl, and the DIX domain of the associated DVl is exposed upon binding of Wnt to $\mathrm{Fz}$ (Chen, 2003; Valenta, 2012). Axin binds to the exposed DIX domain, recruiting the associated destruction complex components to the receptor complex

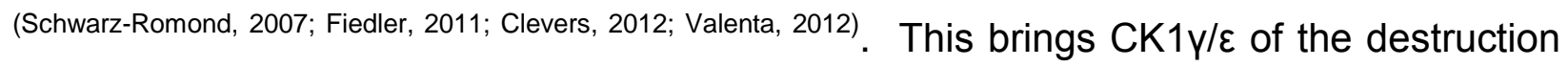
complex into proximity of LRP5/6, allowing CK1Y/ع to phosphorylate LRP5/6, which blocks GSK3 $\beta$ activity (Liu, 2002; Zeng, 2005; Valenta, 2012). This Wnt - induced inhibition of the $\beta$ catenin destruction complex results in the stabilization of $\beta$-catenin in the cytoplasm, allowing $\beta$-catenin to translocate to the nucleus and initiate transcription of Wnt target genes by displacing the co-repressor Groucho and binding to TCF/LEF transcription factors, and recruiting other transcriptional co-activators and histone modifiers including Brg1, CBP/p300, Cdc47, Bcl9, and Pygopus (Li, 2012a; Clevers, 2012; Roose, 1998; Daniels, 2005; Mosimann, 2009; Hecht, 2000; Takemaru, 2000; Li, 2007; Brack, 2009; Schwab, 2007). The mechanisms by which $\beta$-catenin is transported into and out of the nucleus are not completely clear (Krieghoff, 2006; Morgan, 2014; Valenta, 2012). 


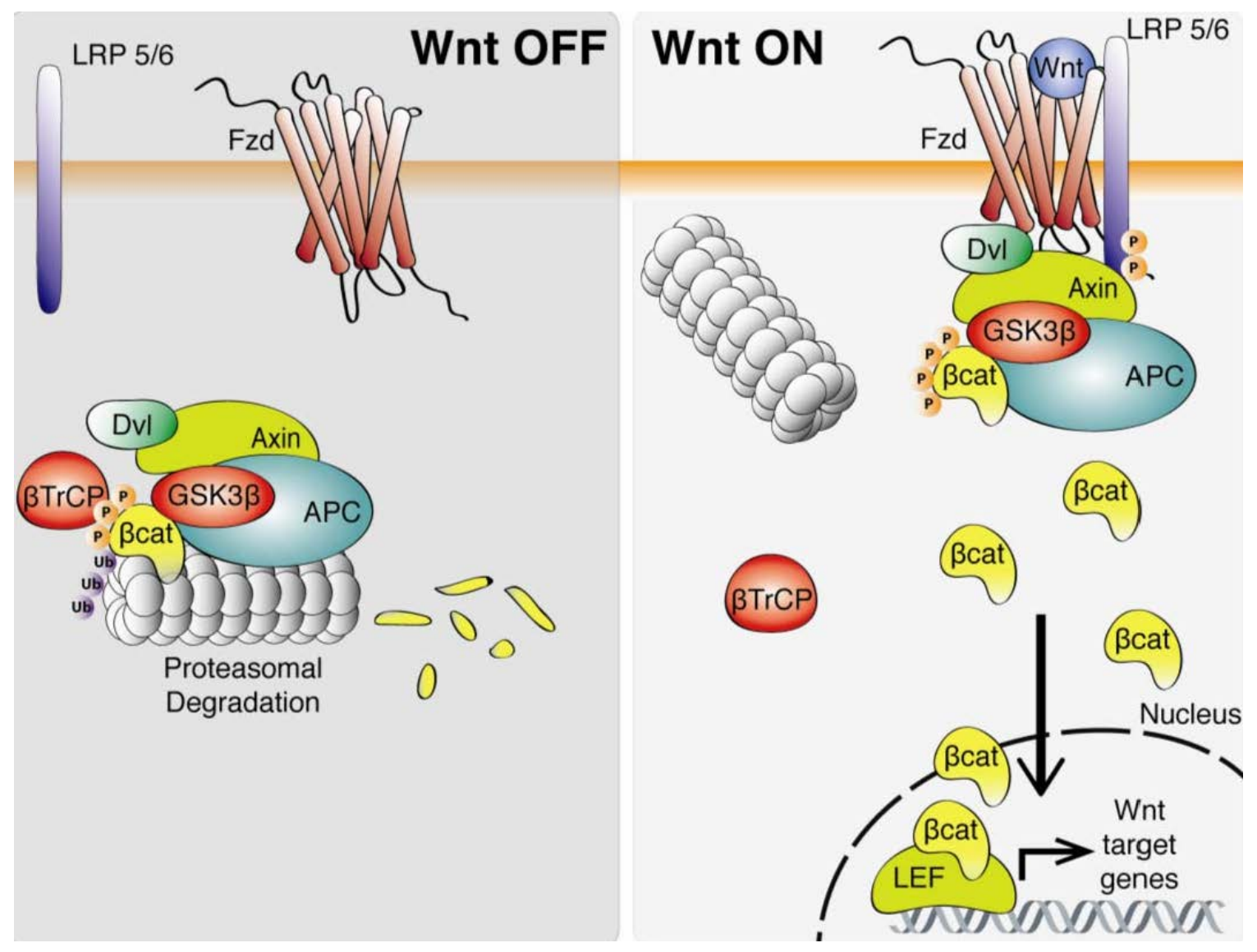

Figure 2: Canonical Wnt Signaling. (Left) In the absence of Wnt ligand, LRP5/6 is not phosphorylated, and the destruction complex, consisting of Dvl, Axin, GSK3- $\beta$, APC, and $\beta$-TrCP, resides in the cytoplasm where it binds, phosphorylates, and ubiquitinates $\beta$-catenin, marking $\beta$-catenin for degradation by the proteasome. (Right) Wnt ligands secreted from nearby cells bind to the Fz receptor, inducing the recruitment of the coreceptors LRP5/6. The assembly of this receptor complex triggers the association of the destruction complex with phosphorylated LRP. The association of the destruction complex with the Wnt/Fz/Lrp5/6 receptor complex blocks the phosphorylation of $\beta$ catenin by GSK3 $\beta$, thus preventing recognition of $\beta$-catenin by $\beta$-TrCP and the subsequent degradation of $\beta$-catenin by the proteasome. The net effect of these interactions is the stabilization of $\beta$-catenin in the cytoplasm, which allows $\beta$-catenin to enter the nucleus where it binds TCF/LEF transcription factors and regulates the transcription of canonical Wnt target genes (Image reprinted with permission from InTechOpen: Image Copyright (c) 2013 Inestrosa, N.C., Varela-Nallar, L. Published in [Wislet, 2013] under CC BY 3.0 license). 


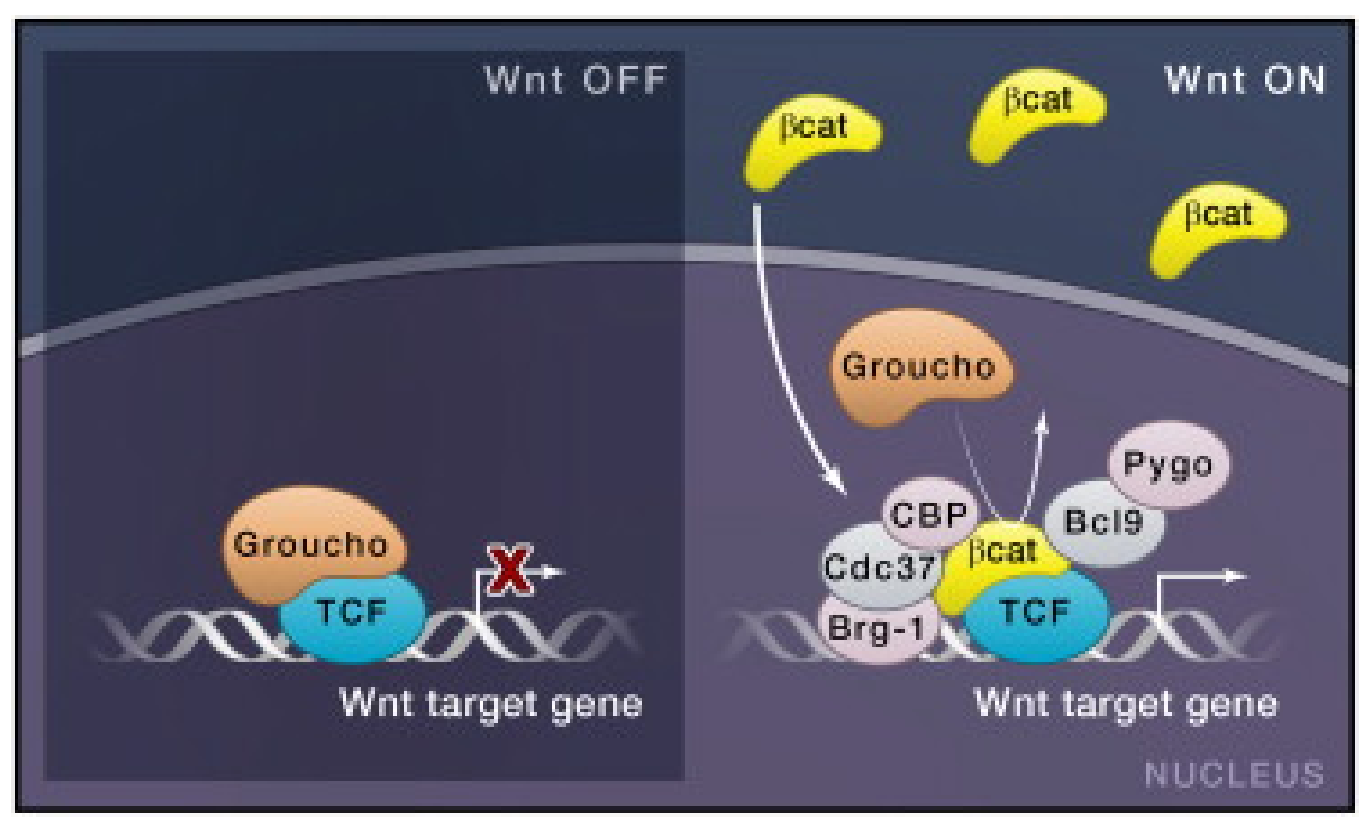

Figure 3: Wnt Signaling in the Nucleus. In the absence of Wnt signals, the corepressor Groucho binds to TCF and represses its target genes. Following the activation of Wnt signaling and the subsequent stabilization of $\beta$-catenin in the cytoplasm, $\beta$-catenin migrates into the nucleus where it replaces Groucho from TCF/LEF and recruits transcriptional coactivators and histone modifiers such as Brg1, CBP, Cdc47, Bcl9, and Pygopus to drive the expression of canonical Wnt target genes (Image reprinted with permission from Elsevier Inc: Cell [Clevers, 2012] Copyright (c) 2012 Elsevier Inc). 


\subsection{4: $\beta$-catenin Subcellular Localization}

Although it is widely accepted that cytoplasmic accumulation of $\beta$-catenin precludes nuclear translocation of $\beta$-catenin, the mechanism by which $\beta$-catenin is transported into and out of the nucleus is unclear (Valenta, 2012). While proteins less than $30 \mathrm{kDA}$ are readily diffusible through the nuclear pores, proteins larger than $50 \mathrm{kDA}$, like $\beta$-catenin (90 kDA), require active transport via the nuclear receptor dependent (importin/exportin) pathways through the nuclear pore complex (NPC) (Morgan, 2014). Interestingly, $\beta$-catenin does not have a recognizable nuclear localization signal (NLS) or nuclear export signal (NES) necessary for transport through nuclear receptor dependent pathways, and does not require Ran-GTPase for transport (Eleftheriou, 2001; Fagotto, 1998; Wiechens, 2001; Yokoya, 1999). Several proteins have been implicated in mediating nuclear import of $\beta$-catenin through the nuclear receptor dependent import pathway (importin $\alpha: \beta$ ) by acting as chaperones, including adenomatous polyposis coli (APC), Ras-related C3 botulinum toxin substrate 1 (Rac1), Smad3/4, forkhead box M1 (FoxM1), insulin receptor substrate 1 (IRS1), cell surface associated mucin 1 (MUC1), B-cell CLL/lymphoma 9 (BCL-9), and the androgen receptor (Henderson, 2000; Wang, 2014; Wu, 2008; Jian, 2006; Li, 2006; Zhang, 2010; Zhang, 2011; Chen, 2005; Li, 2011; Wen, 2003; Brembeck, 2004; Krieghoff, 2006; Mulholland, 2002; Pawlowsk, 2002).

In addition, the TCF/LEF transcription factors that are activated by $\beta$-catenin in the nucleus have also been proposed to chaperone $\beta$-catenin into the nucleus through a nuclear receptor-dependent pathway (Krieghoff, 2006; Molenaar, 1996; Behrens, 1996; Huber, 1996; Simcha, 1998). Similarly, several proteins have been implicated in mediating nuclear export of $\beta$ catenin through the nuclear receptor dependent export pathway by binding chromosome maintenance region 1 (CRM1) and acting as chaperones, including APC, Axin, Chibby, menin, leucine zipper tumor suppressor 2 (LZTS2), p21-activated kinase 4 (PAK4), and Kank (Henderson, 2000; Krieghoff, 2006; Neufeld, 2000a; Neufeld, 2000b; Rosin-Arbesfeld, 2003; Wang, 2014; Cong, 2004; Wiechens, 2004; Li, 2008; Li, 2010; Cao, 2009; Thyssen, 2006; Li, 2012a; Wang, 2006).

In contrast to chaperone-mediated transport of $\beta$-catenin through nuclear receptor dependent pathways, it has been demonstrated that $\beta$-catenin can be transported into and out of the nucleus through chaperone- and nuclear receptor- 
independent pathways (Eleftheriou, 2001; Fagotto, 1998; Wiechens, 2001; Yokoya, 1999). The armadillo repeat sequences 10-12 (R10-12) of $\beta$-catenin directly bind phenylalanine-glycine FxFG or GLFFG repeats (FG repeats) of nucleoporins Nup62, Nup98, Nup153, and RanBP2/Nup358, facilitating transport of $\beta$-catenin through the NPC ${ }^{(\text {Sharma, 2012) }}$. Since the interaction partners of $\beta$-catenin generally bind armadillo repeat sequences 3-8 (R38), R10-12 remain accessible, raising the possibility that $\beta$-catenin may shuttle its interaction partners into and out of the nucleus through these nuclear receptor and RanGTPase independent mechanisms ${ }^{(S h a r m a, 2012)}$. Consistent with these mechanisms of $\beta$ catenin transport, the subcellular localization of $\beta$-catenin may be controlled by retention through the relative abundance of $\beta$-catenin binding partners in the nucleus, cytoplasm, and at the cell membrane (Li, 2012a; Krieghoff, 2006; Morgan, 2014; Valenta, 2012). 


\section{2: Ephrin Signaling}

\subsection{1: Ephrin Signaling}

Wei et al. have previously identified a novel crosstalk between canonical Wnt signaling and ephrin signaling, which likely involves alteration of the stability of $\beta$ catenin, and/or the sub-cellular localization of $\beta$-catenin (Wei, 2010). Ephrin signaling occurs through the interaction of ephrin ligands and Eph receptor tyrosine kinases, and can be unidirectional (forward or reverse) or bidirectional (forward and reverse simultaneously), depending on the directions of signal flow (Pasquale, 2010). Forward signaling occurs when the signal is transduced from the ephrin ligand-expressing cell into the Eph receptor-expressing cell, while reverse signaling occurs in the opposite direction, simultaneously activating molecular pathways downstream of ephrins and Ephs (Pasquale, 2010). Bidirectional signaling occurs when both forward and reverse signaling occur simultaneously via the same Eph/ephrin interaction (Pasquale, 2010). Transmembrane Eph receptors exclusively bind membrane-tethered ephrin ligands, and therefore, ephrin signaling requires cell-cell contact (Klein, 2012). There are two subclasses of Eph receptors, including EphA and EphB (Klein, 2012). In general, EphA receptors bind glycosylphosphotidylinositol (GPI)-linked ephrin-A ligands, while EphB receptors bind transmembrane ephrin-B ligands, however, there are some Eph

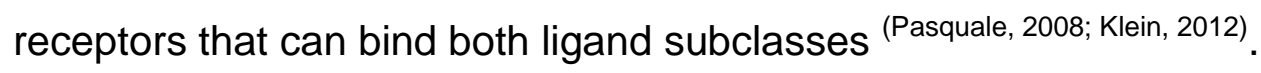

Ephrin ligands and Eph receptors interact in trans, inducing the formation of Eph/ephrin heterodimers (Klein, 2012). These heterodimers bind to other Eph/ephrin heterodimers, forming heterotetramers, which assemble into higher-order clusters through the recruitment of other ligand-bound Eph receptors (Klein, 2012). These higher-order clusters are required for forward and reverse ephrin signaling, and the strength of the forward and reverse signals increases with the recruitment of additional ligand-bound receptors (Klein, 2012; Kania, 2016). Interestingly, Eph receptor clusters can laterally recruit additional Eph receptors independent of ephrins (Klein, 2012). Within the clusters of Eph/ephrins, different sets of the Eph/ephrins may participate in forward and/or reverse signaling simultaneously, resulting in the phenomena of parallel and anti-parallel signaling (Kania, 2016). Parallel signaling occurs when two or more adjacent Eph/ephrins signal simultaneously in the same direction (forward or reverse) ${ }^{(K a n i a, 2016)}$. Anti-parallel signaling occurs when two or more adjacent 
Eph/ephrins signal simultaneously in opposite directions (Kania, 2016). In addition, ephrin-A ligands can interact in cis with co-receptors (Klein, 2012). Eph/ephrins can interact with other ligand/receptor systems, integrating environmental signals and disparate signaling events, producing diverse outcomes in terms of development and tissue homeostasis, maintenance, and function.

Eph receptors have a highly conserved domain organization, consisting of a globular ligand binding domain (LBD), a cysteine rich region that includes a Sushi and an epidermal growth factor (EGF)-like domain, two fibronectin type III domains (FN1 and FN2), a transmembrane (TM) helix, an intracellular juxtamembrane (JM) region that features several conserved tyrosine $(Y)$ residues, a tyrosine kinase domain (TK), a sterile- $\alpha$ motif (SAM) protein-protein interaction domain, and a C-terminal Psd-95, Dlg, and Z01 domain (PDZ)-binding motif (Pasquale, 2008; Klein, 2012). Ephrin-A and ephrin-B ligands possess an extracellular receptor-binding domain (RBD) (Klein, 2012). Ephrin-A ligands are GPI-anchored, while ephrin-B ligands have a TM helix, an intracellular region with several conserved tyrosine residues and a C-terminal PDZ-binding motif (Klein, 2012).

The JM region of Eph receptors suppresses the intrinsic Eph kinase activity through auto-inhibition due to its inactive conformation (Wybenga-Groot, 2001). Activation of Eph receptors results in phosphorylation of tyrosine residues $(P)$ of the JM domain, which relieves the auto-inhibition (Klein, 2012). The kinase domain adopts an active conformation, resulting in phosphorylation of the TK and SAM domains and initiation of downstream signaling events through phosphorylation of intracellular effectors (Klein, 2012). In addition, the tyrosine residues of the intracellular region of ephrin-Bs are phosphorylated in response to binding with Eph receptors ${ }^{\text {(Kullander, 2002). }}$

Forward ephrin signaling activates intrinsic tyrosine kinase activity of the Eph receptors, regulating the recruitment and activity of intracellular effector proteins such as non-catalytic region of tyrosine kinase adaptor protein 1 (Nck1) and Nck2 (also known as Grb4), phosphoinositide 3-kinase (PI3K), Vav2 and Vav3, Src, a2-chimerin, and ephexins (Klein, 2012; Kania, 2016). These effectors are coupled to Ras homology (Rho) subfamily of Ras-like small GTP-ases, including Ras-related C3 botulinum toxin 
substrate 1 (Rac1), cell division control protein 42 homolog (Cdc42), and RhoA (Klein, 2012; Kania, 2016). By regulating the activity of Src family kinases and Ras/Rho family GTP-ases, ephrin signaling affects cytoskeletal dynamics (Klein, 2012; Kania, 2016).

These events lead to the recruitment of PDZ domain-containing proteins, and possibly other effectors, such as the $\mathrm{SH} 2 / \mathrm{SH} 3$ adaptor Grb4, p21 protein (Cdc42/Rac)activated kinase 1 (Pak1), and dedicator of cytokinesis 1 (Dock180), which then elicit cellular responses. Reelin can also bind to ephrin-B1 and ephrin-B3, leading to the activation of disabled 1 (Dab1), which elicits cellular responses.

The mechanism of reverse ephrin-B signaling is not well understood, but one mechanism involves recruitment of Src family kinases and tyrosine phosphorylation of its intracellular domain (Xu, 2002; Klein, 2012; Kania, 2016). These events lead to the recruitment of PDZ domain-containing proteins, and possibly other effectors, such as the $\mathrm{SH} 2 / \mathrm{SH} 3$ adaptor Grb4, p21 protein (Cdc42/Rac)-activated kinase 1 (Pak1), and dedicator of cytokinesis 1 (Dock180), which then elicit cellular responses (Xu, 2002; Klein, 2012; Kania, 2016). Reelin can also bind to ephrin-B1 and ephrin-B3, leading to the activation of disabled 1 (Dab1), which elicits cellular responses (Kania, 2016). Although ephrin-A ligands lack an intracellular region, and therefore are not phosphorylated intracellularly, they also participate in reverse signaling by coupling to co-receptors, such as the Src family tyrosine kinase, Fyn, and the receptor tyrosine kinase, Ret, which elicit cellular responses (Klein, 2012; Kania, 2016).

Termination of Eph/ephrin signaling is achieved by ectodomain cleavage or endocytosis. When co-expressed in the same cell, A distintegrin and metalloprotease domain (ADAM)-type proteases cleave ephrin-A and ephrin-B proteins in cis (Hattori, 2000). When expressed in an adjacent, opposing cell, ADAM-type proteases cleave ephrin-A and ephrin-B proteins in trans ${ }^{(J a n e s, 2005)}$. In addition, Eph receptors are cleaved by metalloproteases and $\mathrm{Y}$-secretase (Bai, 2011). Endocytosis of complete Eph/ephrin complexes from the cell membrane can also achieve termination of Eph/ephrin signaling (Klein, 2012). Ephrin-B can be trans-endocytosed into the EphB-expressing cell and EphB can be trans-endocytosed into the ephrin-B-expressing cell (Klein, 2012). The balance between uni- and bi-directional endocytosis may depend on cellular context, may result 
in unique downstream signaling events, and contributes to the various functions of Eph/ephrins (Marston, 2003; Zimmer, 2003; Pitulescu, 2010; Klein, 2012).

Ephrin signaling affects cytoskeletal dynamics, driving changes in cell shape and cell-cell contacts (Klein, 2012; Kania, 2016). Through these mechanisms, ephrin signaling contributes to cell-cell repulsion/adhesion, segregation, positioning, migration, proliferation, and axon guidance (Klein, 2012; Kania, 2016). These cellular responses underlie the roles of ephrin signaling in development, such as patterning, morphogenesis, and tissue boundary formation. These cellular responses also underlie the roles of ephrin signaling in tissue homeostasis, maintenance, and function in adult tissues (Klein, 2012; Kania, 2016). Due to these critical roles of ephrin signaling, aberrant ephrin signaling is implicated in developmental defects and diseases including neuronal defects, bone remodeling diseases, diabetes, and cancer (Pasquale, 2008; Klein, 2012; Pasquale, 2010). 

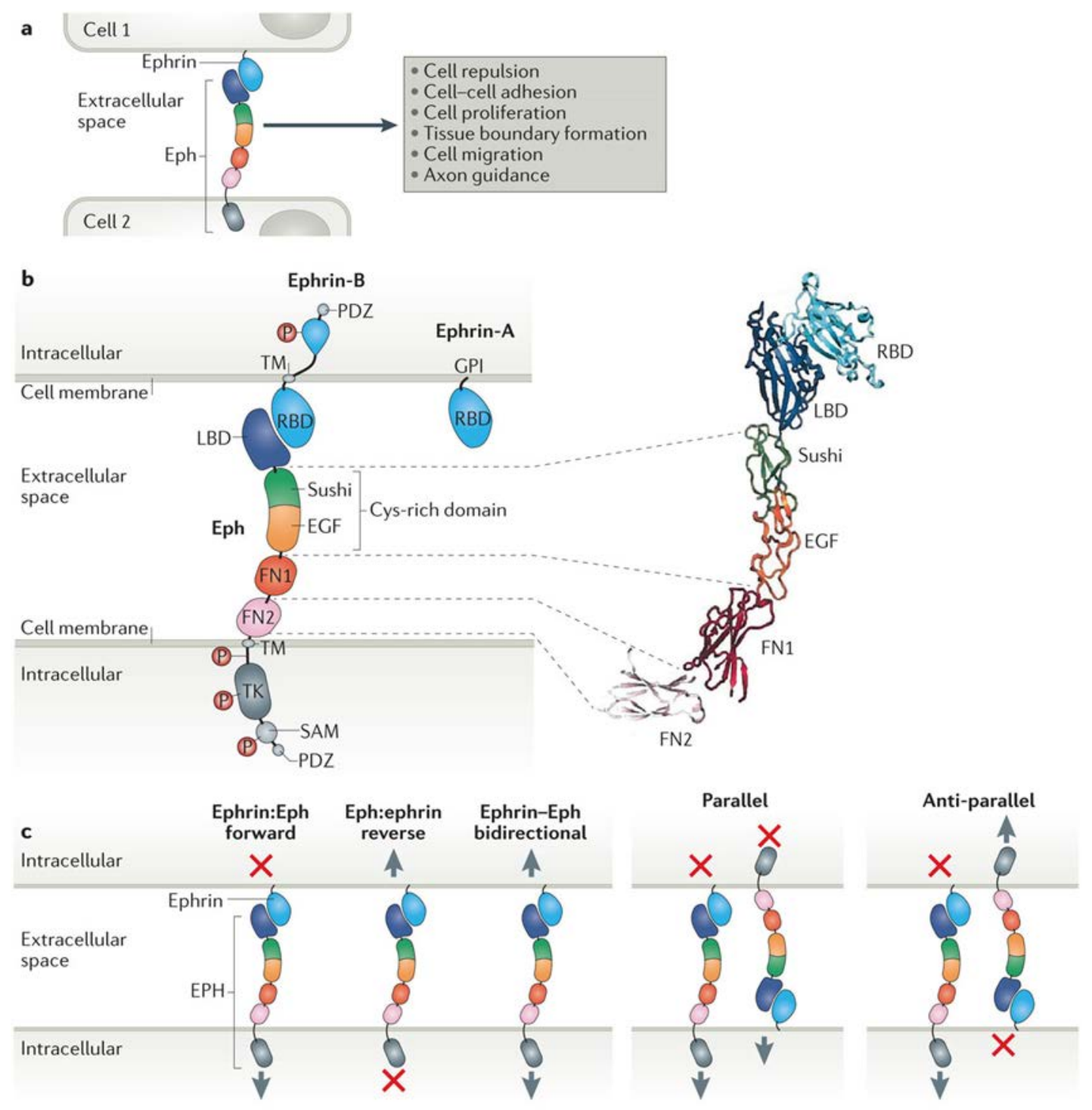

Nature Reviews | Molecular Cell Biology

Figure 4: Eph/ephrin Domain Organization and Signaling Modes. a) Transmembrane Eph receptor tyrosine kinases bind membrane-tethered ephrin ligands in trans, and therefore, ephrin signaling requires cell-cell contact. Ephrin signaling affects cytoskeletal dynamics, driving changes in cell shape and cell-cell contacts. Through these mechanisms, ephrin signaling contributes to cell-cell repulsion/adhesion, segregation, positioning, migration, proliferation, and axon guidance. These cellular responses underlie the roles of ephrin signaling in development, such as patterning, morphogenesis, and tissue boundary formation, as well as the roles of ephrin signaling in tissue homeostasis, maintenance, and function in adult tissues. b) Eph receptors (left) have a highly conserved domain organization, consisting of a globular ligand binding domain (LBD), a cysteine rich region that includes a Sushi and an epidermal growth factor (EGF)-like domain, two fibronectin type III domains (FN1 and FN2), a transmembrane (TM) helix, an intracellular juxtamembrane $(\mathrm{JM})$ region that features several conserved tyrosine $(\mathrm{Y})$ residues, a 
tyrosine kinase domain (TK), a sterile- $\alpha$ motif (SAM) protein-protein interaction domain, and a C-terminal Psd-95, Dlg, and Z01 domain (PDZ)-binding motif. Ephrin-A and ephrin-B ligands possess an extracellular receptor-binding domain (RBD). Ephrins (right) are divided into $A$ and $B$ classes based on their affinity for EphA or EphB receptors and whether they are tethered to the membrane via $a$ glycosylphosphatidylinositol GPI linkage (class A), or as type-I transmembrane proteins (class B). Unlike the GPI-anchored ephrin-A ligands, ephrin-B ligands have a TM helix, an intracellular region with several conserved tyrosine residues and a C-terminal PDZbinding motif. The JM region of Eph receptors suppresses the intrinsic Eph kinase activity through auto-inhibition due to its inactive conformation. Activation of Eph receptors results in phosphorylation of tyrosine residues $(P)$ of the JM domain, which relieves the auto-inhibition. The kinase domain adopts an active conformation, resulting in phosphorylation of the TK and SAM domains and initiation of downstream signaling events through phosphorylation of intracellular effectors. Phosphorylation of the tyrosine residues of the intracellular domains of ephrin-B ligands also occurs in response to Eph-ephrin interaction, and is involved in reverse signaling. In addition, the tyrosine residues of the intracellular region of ephrin-Bs are phosphorylated in response to binding with Eph receptors. c) Ephrin signaling can be unidirectional (forward or reverse) or bidirectional (forward and reverse simultaneously), depending on the direction(s) of signal flow. Arrows indicate signaling events, and X's indicate the absence of signaling. Forward signaling occurs when the signal is transduced from the ephrin ligand-expressing cell into the Eph receptor-expressing cell, while reverse signaling occurs in the opposite direction. Bidirectional signaling occurs when both forward and reverse signaling occur simultaneously via the same Eph/ephrin interaction, simultaneously activating molecular pathways downstream of ephrins and Ephs. Because there may be multiple Eph/ephrin (A and/or B) and/or ephrin/Eph (A and/or B) interactions occurring simultaneously at the junctions between two cells, the phenomena of parallel and anti-parallel signaling emerge. Parallel signaling occurs when two or more Eph/ephrins signal simultaneously in the same direction (forward or reverse), propagating forward or reverse signals in the same direction. Anti-parallel signaling occurs when two or more Eph/ephrins signal simultaneously in opposite directions, simultaneously propagating forward signals in one direction and reverse signals in the opposite direction (Image reprinted with permission from Macmillan Publishers Ltd: Nature Reviews Molecular Cell Biology [Kania, 2016], Copyright (c) 2016). 

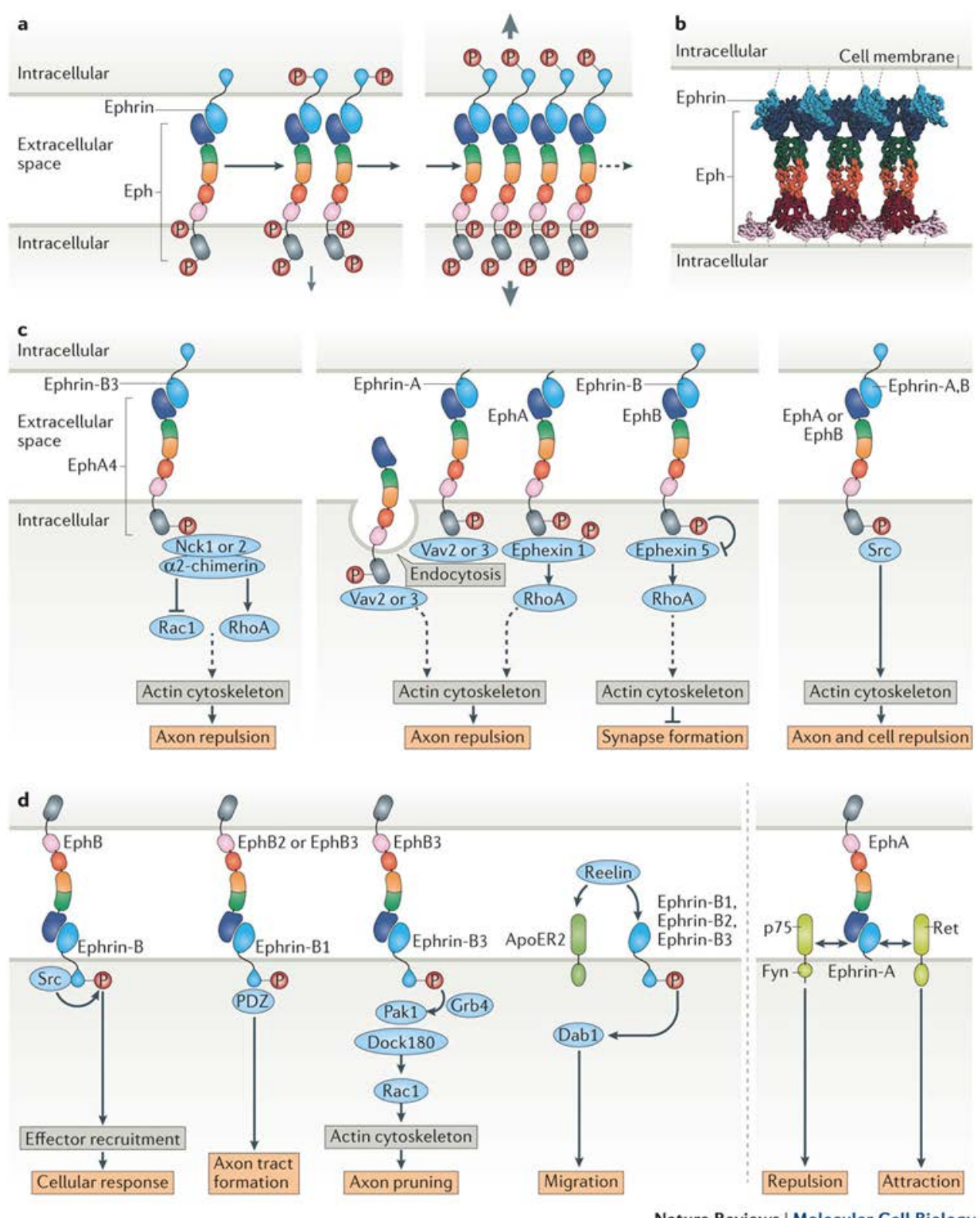

Nature Reviews | Molecular Cell Biology

Figure 5: Eph/ephrin Complexes and Receptor Clustering, and Downstream Molecular Pathways and Cellular Responses. a) Ephrin ligands and Eph receptors interact in trans, inducing the formation of Eph/ephrin heterodimers. These heterodimers bind to other Eph/ephrin heterodimers, forming heterotetramers, which assemble into higher-order clusters through the recruitment of other ligand-bound Eph receptors. These higher-order clusters are required for forward and reverse ephrin signaling, and the strength of the forward and reverse signals increases with the recruitment of additional ligand-bound receptors. Interestingly, Eph receptor clusters can laterally recruit additional Eph receptors independent of ephrins. The tyrosine phosphorylation events $(P)$, as described in Figure 4, are also shown. b) Crystal structure of a higher-order cluster of an ephrin-A5-EphA2 complex. c) Schematic representations of downstream molecular pathways activated downstream of forward ephrin signaling that affect cytoskeletal changes underlying various cellular responses. 
Forward ephrin signaling activates intrinsic tyrosine kinase activity of the Eph receptors, regulating the recruitment and activity of intracellular effector proteins such as noncatalytic region of tyrosine kinase adaptor protein 1 (Nck1) and Nck2 (also known as Grb4), phosphoinositide 3-kinase (PI3K), Vav2 and Vav3, Src, a2-chimerin, and ephexins. These effectors are coupled to Ras homology (Rho) subfamily of Ras-like small GTP-ases, including Ras-related C3 botulinum toxin substrate 1 (Rac1), cell division control protein 42 homolog (Cdc42), and RhoA. By regulating the activity of Src family kinases and Ras/Rho family GTP-ases, ephrin signaling affects cytoskeletal dynamics. d) The mechanism of reverse ephrin-B signaling is not well understood, but one mechanism involves recruitment of Src family kinases and tyrosine phosphorylation of its intracellular domain. These events lead to the recruitment of PDZ domaincontaining proteins, and possibly other effectors, such as the SH2/SH3 adaptor Grb4, p21 protein (Cdc42/Rac)-activated kinase 1 (Pak1), and dedicator of cytokinesis 1 (Dock180), which then elicit cellular responses. Reelin can also bind to ephrin-B1 and ephrin-B3, leading to the activation of disabled 1 (Dab1), which elicits cellular responses. Although ephrin-A ligands lack an intracellular region, and therefore are not phosphorylated intracellularly, they also participate in reverse signaling by coupling to co-receptors, such as the Src family tyrosine kinase, Fyn, and the receptor tyrosine kinase, Ret, which elicit cellular responses (Image reprinted with permission from Macmillan Publishers Ltd: Nature Reviews Molecular Cell Biology [Kania, 2016], Copyright (c 2016). 


\section{3: Canonical Wnt - ephrin-B Crosstalk}

\subsection{1: Evidence of Canonical Wnt - ephrin-B Crosstalk}

Wnt signaling and ephrin-B signaling are both involved in regulation of the intestinal stem cell niche, and the normal tissue homeostasis of the intestine (Clevers, 2006b). The small intestine contains protrusion known as villi, and the basal areas between these villi are known as crypts. The cells in the intestinal crypts are stem cells and Paneth cells, which express EphB receptors (EphB2, EphB3, and EphB4) (Clevers, 2006b; Kania, 2016). As these cells differentiate, they proliferate and migrate up the villi from the intestinal crypt and come into contact with the differentiated cells at the apical portion of the villi, which express ephrin-B1 and ephrin-B2 (Clevers, 2006b; Kania, 2016). Cellcell contact and the initiation of EphB/ephrin-B signaling between the ephrin-B1/B2 expressing cells and the migrating EphB cells from the crypt leads to the loss of EphB expression in these cells, allowing for their differentiation and normal tissue homeostasis (Clevers, 2006b; Kania, 2016). These events result in the formation of a gradient of EphB expression that is strongest at the base of the crypts and weakest at the apical portion of the villi, and an opposing ephrin-B gradient that is strongest at the apical portion of the villi and weakest at the base of the crypts (Clevers, 2006b; Kania, 2016). Loss of ephrin-B signaling disrupts cell proliferation and positioning along the villus - crypt axis (Kania, 2016). Mutations in the tumor suppressor gene APC (APC ${ }^{\text {mut }}$ ) leads to the constitutive activation of canonical Wnt signaling, and the transformation of these cells into tumor-initiating cells (cells inside the box labeled APC ${ }^{\text {mut }}$ ) (Clevers, 2006b). These proliferate and migrate up the crypt, accumulating at the villi and forming benign polylike outgrowths, or adenomas (Clevers, 2006b). These tumor-initiating cells express high levels of EphB receptors, and contact of these cells with normal differentiated cells expressing high levels of ephrin-B ligands at the apical portion of the villi results in activation of ephrin-B signaling (Clevers, 2006b). EphB repulsive signals limit the spread of the tumor. These findings illustrate how the orchestration of canonical Wnt and ephrin signaling programs can contribute to normal development and tissue homeostasis, and disruption of these signaling gradients can result in colorectal cancer. 
Direct inhibition of Wnt signaling by ephrin-B signaling was suggested by the finding that the metalloprotease ADAM13 cleaves ephrin-B1, permitting canonical Wnt signaling during cranial neural crest (CNC) induction in Xenopus tropicalis embryos (Wei, 2010). Furthermore, wild-type Xenopus ephrin-B1 (ephrin-B1WT) and ephrin-B1 $\Delta \mathrm{C}(\mathrm{a}$ mutant ligand that lacks the cytoplasmic tail and hence only promotes forward, but not reverse, ephrin signaling) inhibit Wnt reporter (TOP/FOP FLASH) expression when Wnt signaling is activated by Wnt8 in Xenopus tropicalis embryos and by Wnt3a in human embryonic kidney (HEK293T) cells (Wei, 2010).

It has been shown previously that decreased nuclear $\beta$-catenin is a consequence of increased ephrin signaling through Eph receptors during carcinogenesis (Chiu, 2009). Taken together, these data indicate a novel crosstalk between Wnt and ephrin signaling axes in which ephrin-B signaling antagonizes canonical Wnt signaling. The molecular mechanism that mediates this antagonistic interaction is unknown. Furthermore, this antagonistic interaction provides a unique system in which to investigate the mechanisms of inhibition of canonical Wnt signaling. Canonical Wnt signaling can be modulated through interactions at various levels of the canonical Wnt signaling axis including 1) ligand - receptor and receptor - receptor interactions, 2) $\beta$-catenin stability, 3) $\beta$-catenin localization, and 4) $\beta$-catenin/TCF/LEF/DNA interactions (Figure 8). Therefore, we aimed to gain insight into the mechanisms of ephrin-B antagonism of canonical Wnt signaling by differentiating among these possibilities. 


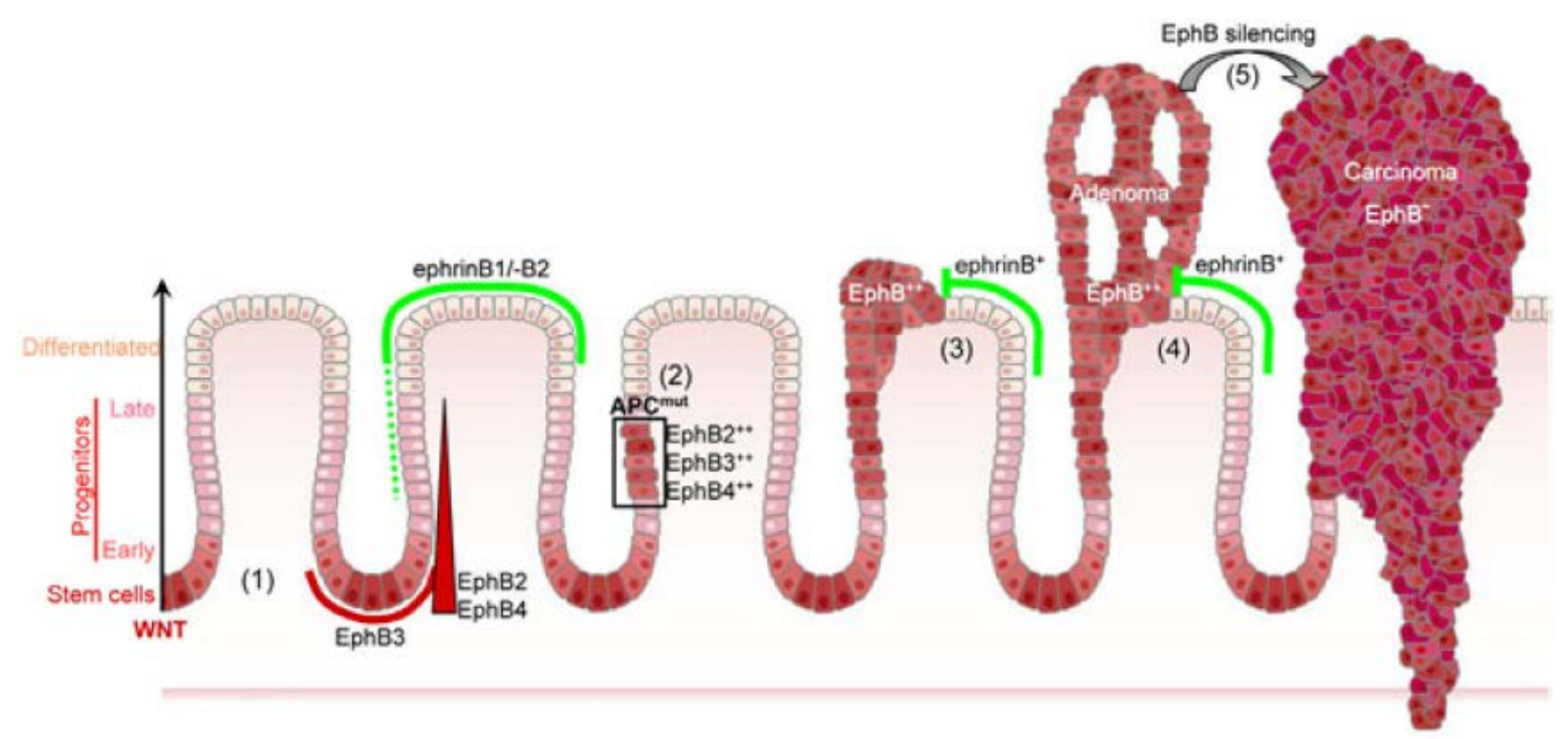

Figure 6: Canonical Wnt and Eph/ephrin Interactions in the Intestinal Stem Cell Niche and Colorectal Cancer Progression. The small intestine contains protrusion known villi, and the basal areas between these villi are known as crypts. 1) The cells in the intestinal crypts are stem cells and Paneth cells, which express EphB receptors (EphB2, EphB3, and EphB4). As these cells differentiate, they proliferate and migrate up the villi from the intestinal crypt and come into contact with the differentiated cells at the apical portion of the villi, which express ephrin-B1 and ephrin-B2. Cell-cell contact and the initiation of EphB/ephrin-B signaling between the ephrin-B1/B2 expressing cells and the migrating EphB cells from the crypt leads to the loss of EphB expression in these cells, allowing for their differentiation and normal tissue homeostasis. These events result in the formation of a gradient of EphB expression that is strongest at the base of the crypts and weakest at the apical portion of the villi, and an opposing ephrin$B$ gradient that is strongest at the apical portion of the villi and weakest at the base of the crypts. Loss of ephrin-B signaling disrupts cell proliferation and positioning along the villus - crypt axis. 2) Mutations in the tumor suppressor gene APC (APC ${ }^{\text {mut }}$ ) leads to the constitutive activation of canonical Wnt signaling, and the transformation of these cells into tumor-initiating cells (cells inside the box labeled APC ${ }^{\text {mut }}$ ). These proliferate and migrate up the crypt, accumulating at the villi and forming benign poly-like outgrowths, or adenomas. 3) These tumor-initiating cells express high levels of EphB receptors, and contact of these cells with normal differentiated cells expressing high levels of ephrin-B ligands at the apical portion of the villi results in activation of ephrin-B signaling. 4) EphB repulsive signals limit the spread of the tumor (Image reprinted with permission from Eduard Battle Lab, IRB Barcelona [Batlle, 2007]). 


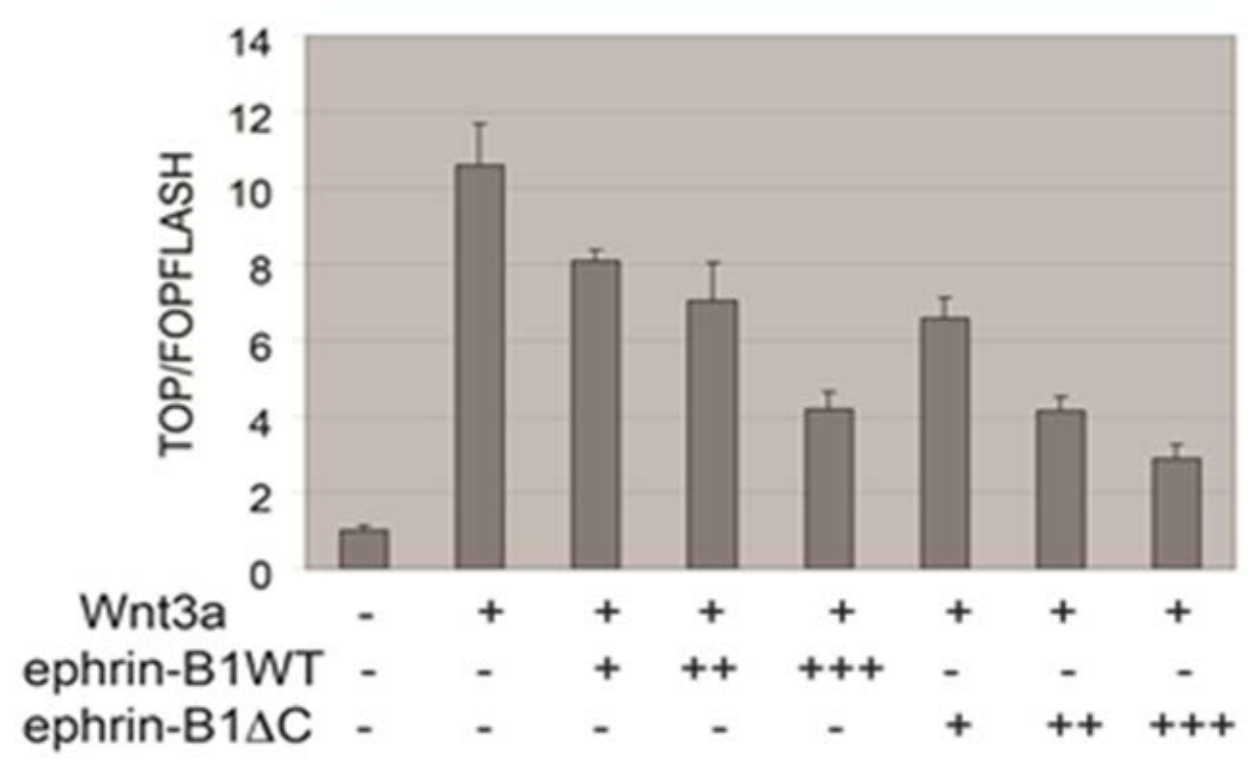

Figure 7: Wild-type ephrin-B and ephrin-B1 $\Delta C$ Inhibit Wnt3a - Induced Reporter Activity. HEK293T cells were transfected with pTOP FLASH (TOP) and pFOP FLASH (FOP) and the indicated constructs and cultured for $\sim 40$ hours. Cell lysates were processed for luciferase assays. A representative experiment performed in triplicate is shown here. Results are presented as average ratios of TOP vs. FOP luciferase activity, and the error bars represent standard deviations. *: $P<0.05, * \star: P<0.01,{ }^{\star} * * P$ $<0.001$ (Image reprinted with permission from Elsevier Inc: Developmental Cell [Wei, 2010; supplement] Copyright (C) 2010 Elsevier Inc). 


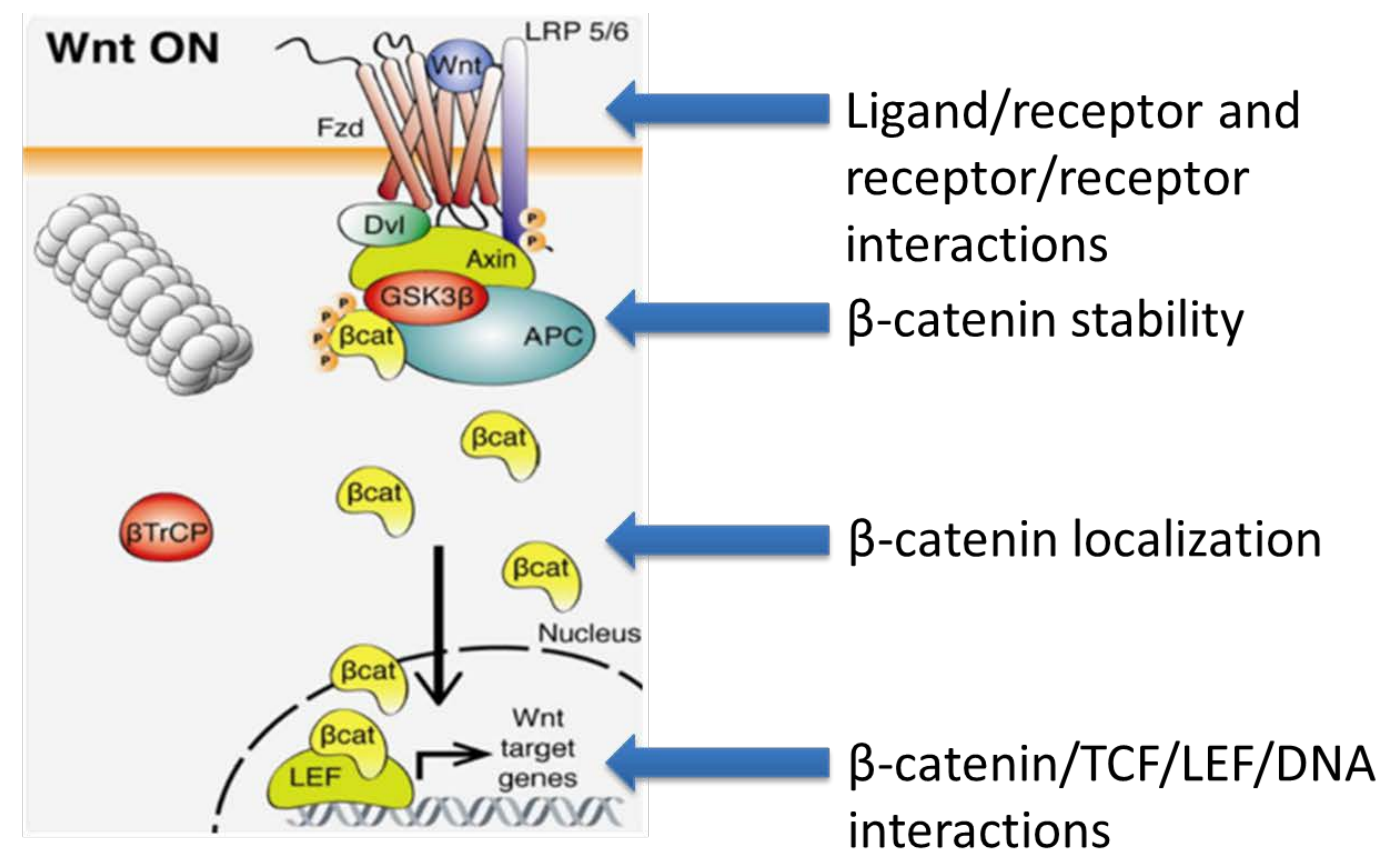

Figure 8: Regulation of the Wnt Signaling Axis. Canonical Wnt signaling can be modulated through interactions at various levels of the canonical Wnt signaling axis including 1) ligand - receptor and receptor - receptor interactions, 2) $\beta$-catenin stability, 3) $\beta$-catenin localization, and 4) $\beta$-catenin/TCF/LEF/DNA interactions (Image adapted with permission from InTechOpen: Image Copyright (c) 2013 Inestrosa, N.C., VarelaNallar, L. Published in [Wislet, 2013] under CC BY 3.0 license). 


\subsection{2: Regulators of $\beta$-catenin Stability and Localization}

$\beta$-catenin levels and $\beta$-catenin subcellular localization are affected by interactions with protein modifiers within the cell, and other cellular signaling pathways. $\beta$-catenin is modified by GSK3 $\beta$ and C-Jun N-terminal kinase 1 and 2 (JNK1, JNK2), and adenomatous polyposis coli (APC) and Ras-related C3 botulinum toxin substrate 1 (Rac1) affect $\beta$-catenin subcellular localization (Liu, 2002; Zeng, 2005; Hu, 2008; Hu, 2009; Henderson, 2000; Wang, 2014; Wu, 2008). In addition, classical cadherins, such as E-cadherin, sequester $\beta$ catenin to the cell membrane through the binding of $\beta$-catenin to the cytoplasmic tail of E-cadherin, resulting in a decrease in nuclear $\beta$-catenin and Wnt signaling activation (Conacci-Sorrell, 2003). Therefore, dense cell cultures have lower nuclear $\beta$-catenin and Wnt signaling activation than sparse cell cultures (Conacci-Sorrell, 2003). These effectors of $\beta$ catenin stability and $\beta$-catenin subcellular localization represent potential nexuses through which ephrin-B signaling may interact with Wnt signaling.

\subsection{3: c-Jun N-terminal kinase 1 and 2 (JNK1, JNK2)}

One intriguing possible mediator of the ephrin-B induced antagonism of canonical Wnt signaling is JNK. JNK is a downstream target of forward ephrin signaling and can prevent nuclear $\beta$-catenin accumulation (Stein, 1998; Liao, 2006). In addition, it has previously been demonstrated that JNK1 and JNK2 can affect the stability, amount and subcellular localization of $\beta$-catenin (Hu, 2008; Hu, 2009; Wu, 2008). JNK1 and JNK2 cause a reduction in $\beta$-catenin in HEK293T cells, with JNK2 causing a greater reduction in $\beta$ catenin than JNK1, and this reduction in $\beta$-catenin occurs through the ubiquitinproteasome system (UPS) and is mediated by GSK ${ }^{(\mathrm{Hu}, 2008 ; \mathrm{Hu}, 2009)}$. Furthermore, preliminary data from Laura Christian, a former post-doc in the Wei lab, indicates that co-transfection of ephrin-B1 $\Delta C$ and EphB2 in HeLa cells results in an increase in JNK activity (Figure 9) (Christian et al., unpublished). Therefore, we propose that ephrin-B signaling antagonizes canonical Wnt signaling by activating JNK, preventing nuclear accumulation of $\beta$-catenin and inducing degradation of $\beta$-catenin via the UPS mediated by GSK $\beta$. 


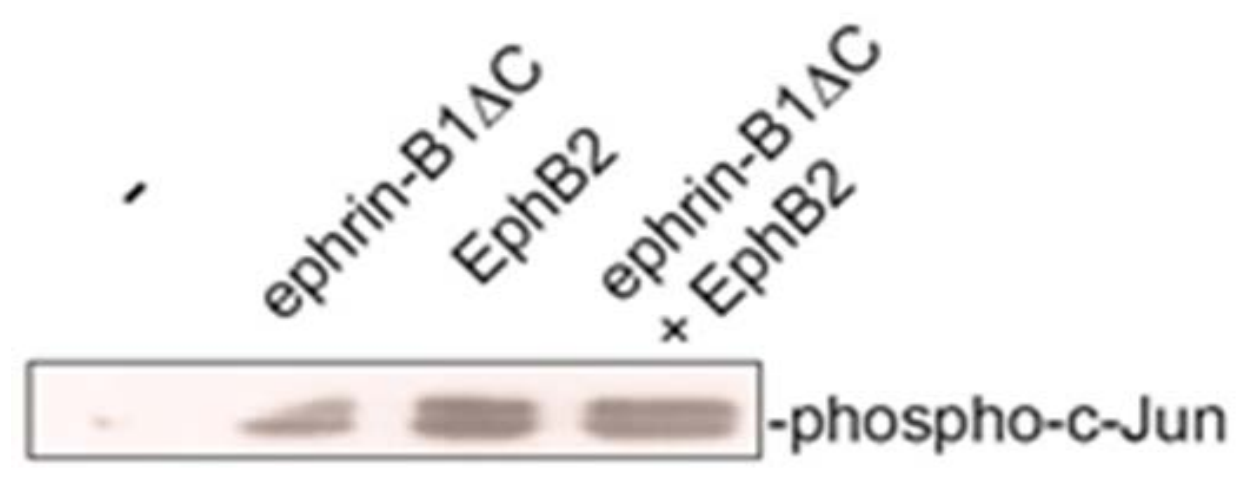

Figure 9: Ephrin-B Signaling Activates c-Jun N-terminal kinase (JNK). HeLa cells were transfected to express the indicated proteins, and in vitro JNK activity assays were carried out using a JNK Kinase Assay Kit (Cell Signaling Technology; 8794). JNK was pulled down from cell lysates by using an a JNK antibody, and incubated with recombinant c-Jun protein. Western blot was performed by using an a phospho-c-Jun antibody (Data courtesy of Dr. Laura Christian et al., unpublished). 


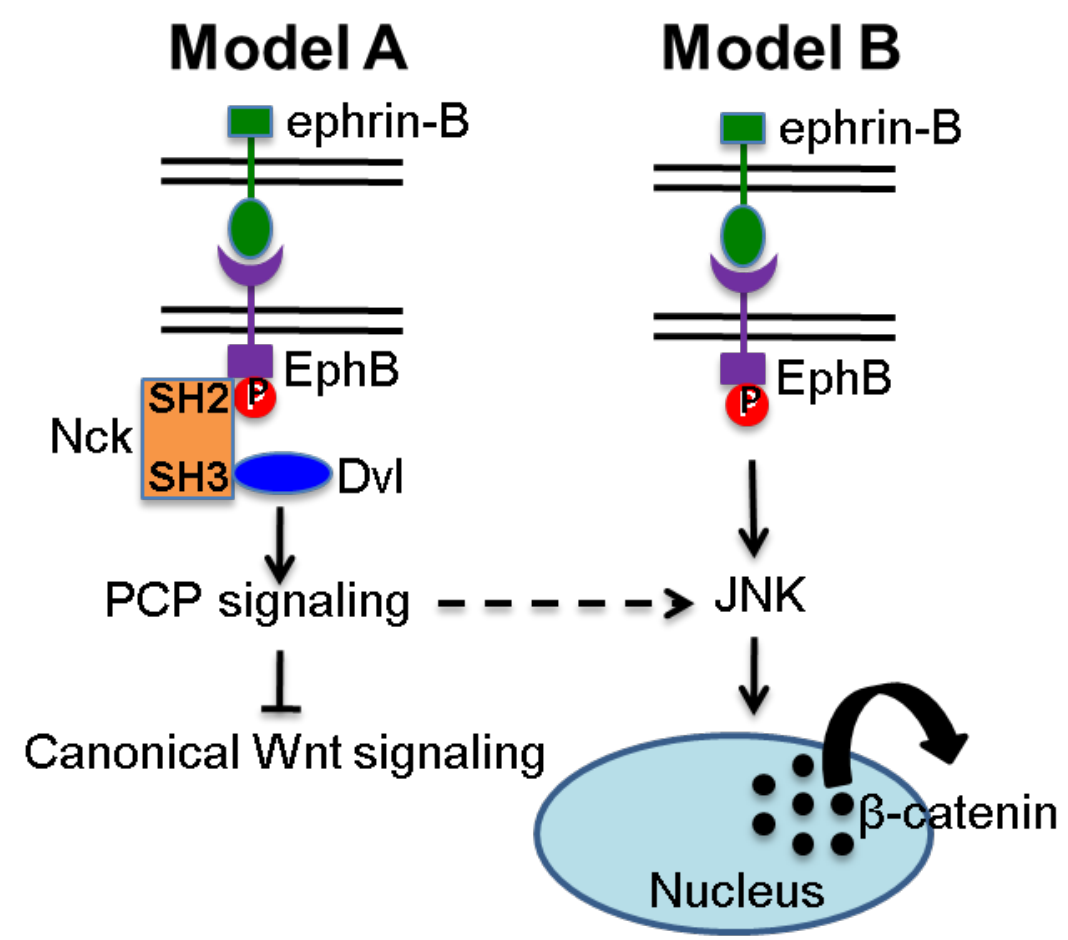

Figure 10: Proposed Models for JNK-mediated ephrin-B Antagonism of Canonical Wnt Signaling. (Model A) Forward ephrin-B signaling results in intracellular activation of Dvl. Dvl activates downstream signaling events and initiates PCP signaling, which inhibits canonical Wnt signaling. (Model B) Forward ephrin-B signaling results in downstream activation of JNK. JNK interacts with and modifies $\beta$-catenin, triggering nuclear export of $\beta$-catenin. 


\section{Chapter 2: Specific Aims}

\section{1: Specific Aims}

1) To test if the ephrin-B antagonism of canonical Wnt signaling first described in Xenopus laevis is conserved in mammals.

2) To determine the cellular processes that mediate this crosstalk by investigating the effects of ephrin-B signaling on the $2 a$ ) stabilization and $2 b$ ) subcellular localization of $\beta$-catenin.

3) To determine how downstream effectors of ephrin-B signaling may interact with $\beta$-catenin, mediating this crosstalk. 


\section{2: Specific Aims Approaches}

Aims 1 and 2a were addressed using the TOP/FOP FLASH luciferase reporter assay as a read-out of activation of canonical Wnt signaling. Overexpression of canonical Wnt ligands (Wnt3a or Wnt8), wild-type $\beta$-catenin ( $\beta$-catenin WT), or a $\beta$ catenin mutant $(\beta$-catenin*), or lithium chloride $(\mathrm{LiCl})$ treatment were used to activate TOP/FOP FLASH reporter activity in human embryonic kidney (HEK293T) cells. LiCl inhibits GSK3 $\beta$, blocking phosphorylation of $\beta$-catenin and preventing its degradation by the UPS (Zhang, 2003). Similarly, $\beta$-catenin* has serine (S)/threoinine $(T)$ to aspartic acid (D) point mutations at Ser33, Ser37, Thr41, and Ser45, and cannot be modified by the destruction complex. Expression of a mouse ephrin-B1 ligand lacking the cytoplasmic domain, ephrin-B1 $\Delta C$, in the presence of an activator of canonical Wnt (overexpression of Wht ligands, $\beta$-catenin, or $\beta$-catenin*, or $\mathrm{LiCl}$ treatment) was tested to determine if ephrin-B antagonism of canonical Wnt signaling reported in Xenopus is conserved in mammals, and whether or not this effect depends on the normal function of the endogenous regulation of $\beta$-catenin stability via GSK3 $\beta$.

Aim $2 \mathrm{a}$ was addressed by measuring changes in total cellular $\beta$-catenin in HEK293T cell lysates in response to canonical Wnt and ephrin-B signaling. The relevant Western blots were quantified using Image J (Schindelin, 2012; Walter, 2010; Eliceiri, 2012). In accordance with Aim $2 b$, the subcellular localization of $\beta$-catenin was observed using confocal immunofluorescence microscopy. These images were prepared and analyzed using the image analysis software Adobe Illustrator, Fiji (Image J), and Vaa3d (Schindelin, 2012; Walter, 2010; Eliceiri, 2012; Peng, 2010; Peng, 2014). This analysis allowed visualization of the subcellular localization of $\beta$-catenin (in 3-D) in response to canonical Wnt and ephrin-B signaling.

Aim 3 was addressed by investigating the role of JNK in mediating the ephrin-B antagonism of canonical Wnt signaling. The activation of JNK by ephrin-B signaling was reaffirmed using an in vitro JNK assay (Christian et al., unpublished data). Inhibition of JNK using the JNK inhibitor, SP600125, and analysis of the corresponding effects on $\mathrm{LiCl}$ induced activation of canonical Wnt signaling (TOP/FOP FLASH) was used to indicate 
whether or not inhibition of JNK activity is sufficient to reverse the antagonistic effect of ephrin-B on canonical Wnt signaling (Bennett, 2001). 


\section{Chapter 3: Methods}

A combination of cell-based assays, biochemical techniques, and confocal immunofluorescence microscopy in HEK293T cells were used to investigate the molecular mechanisms of ephrin-B antagonism of canonical Wnt signaling.

pCS2 vector-based plasmids were constructed previously including Mus musculus HA-ephrin-B1 $\Delta \mathrm{C}$ (ephrin-B1 $\Delta \mathrm{C}$ ), wild-type Xenopus laevis $\beta$-catenin ( $\beta$ cateninWT), a mutant Xenopus laevis $\beta$-catenin that is constitutively active, $\beta$-catenin* (S33/37/41/T45D), Wnt3a, and Wnt8. In addition, pTOP FLASH (TOP) and pFOP FLASH (FOP) luciferase reporter plasmids were obtained commercially (EMD Millipore; 21-170).

HEK293T cells were seeded and grown in Dulbecco's Modified Eagle Medium (DMEM) high glucose (Gibco; 11965-092) supplemented with 5\% fetal bovine serum (FBS) and 1:100 penn/strep at a controlled density for $\sim 24$ hours. When the pan-JNK inhibitor, SP600125 (abcam; ab120065), was used, it was mixed with fresh DMEM media, and added to the appropriate wells, replacing the existing media after $\sim 24$ hours of growth post-seeding. Auto $\mathrm{H}_{2} \mathrm{O}$ (vehicle control for $\mathrm{LiCl}$ ) and DMSO vehicle controls were added in the same fashion as SP60125, as necessary, to evaluate any potential effects of these vehicles on the results. Lipofectamine-based transfections (Invitrogen; L3000015) of these plasmids were performed after $\sim 24$ hours of growth post-seeding. For immunofluorescence experiments, the cells were grown on poly-D-lysine (molecular weight 70,000-150,000) coated coverslips (Sigma; P6407). Following transfection, the cells were incubated at $37^{\circ} \mathrm{C}$ for $\sim 24$ hours. The cells were then harvested and lysed in preparation for TOP/FOP FLASH luciferase reporter assay, Western blot, or other biochemical analysis, or fixed in preparation for immunofluorescence treatment and confocal microscopy.

The TOP/FOP FLASH luciferase reporter assay was performed according to the manufacturer's protocol and recommendation (Promega; E1500). The Spectra max GeminiXPS plate reader and the SoftMax Pro 6 software from Molecular Devices were used in luminescence mode to measure the luminescence in relative luminescence 
units (RLU) of the assayed cell lysate samples. The average and standard deviation of the RLU measurements of three replicates of each treatment performed in parallel were calculated using Microsoft Excel.

The Western blots were blocked with $5 \%$ bovine serum albumin (BSA) for one hour at room temperature with shaking. Polyclonal rabbit $\alpha \beta$-catenin (Sigma; C2206) was applied at a dilution of $1: 4,000$ and incubated overnight at $4^{\circ} \mathrm{C}$ with shaking. Polyclonal goat a rabbit horseradish peroxidase (HRP) secondary antibody (Sigma; A0545) was applied to each Western blot at a dilution of 1:25,000, and incubated for 30 minutes at room temperature with shaking. The HRP substrate was applied, and the Western blots were imaged using the ProteinSimple FluorChem $\mathrm{Q}$ system and the AlphaView 3.4.0 software. The Western blots were stripped and blotted for $\beta$-actin by applying monoclonal mouse $\alpha \beta$-actin HRP clone AC-15 (Sigma; A3854) at a dilution of 1:25,000, and incubated for $30 \mathrm{~min}$ at room temperature with shaking. The HRP substrate was applied and the Western blots were imaged as described above. Two of the three Western blots were re-stripped and blotted for E-cadherin by applying monoclonal rabbit $\alpha$ E-cadherin clone 24E10 (Cell Signaling Technology; 3195) at a dilution of $1: 1,000$, and incubating overnight at $4^{\circ} \mathrm{C}$ with shaking. The HRP substrate was applied to the Western blots and they were imaged as described above. The Western blot images were quantified by calculating the integrated density of each band using the Image analysis software Image J (Schindelin, 2012; Walter, 2010; Eliceiri, 2012). The normalized values (adjusted relative density) of the signals were obtained by dividing the integrated density of the protein of interest band by the integrated density of the $\beta$ actin band of that same sample. The average and standard deviation of the adjusted relative density values of $\beta$-catenin under each treatment from three replicate Western blots were calculated.

For immunofluorescence, the cells were fixed with 1:1 methanol:acetone. The cells were blocked with blocking buffer (5\% lamb serum, $0.3 \%$ Triton X-100 in $1 \mathrm{x}$ phosphate buffered saline (PBS)) for one hour at room temperature in a humid, lighttight box. Polyclonal rabbit a $\beta$-catenin (Sigma; C2206) and monoclonal mouse a HA clone HA-7 (Sigma; H9658) primary antibodies were applied at dilutions of 1:1000 as 
necessary, and incubated overnight at $4^{\circ} \mathrm{C}$ in a humid, light-tight box. Donkey a rabbit CF633 (Biotium; 20125) and polyclonal donkey a mouse Alexa 488 (Jackson ImmunoResearch Laboratories; 715-545-150) fluorescently conjugated secondary antibodies were each applied at the concentration $10 \mu \mathrm{g} / \mathrm{mL}$, as necessary, to label $\beta$ catenin and ephrin-B1 $\triangle \mathrm{C}(\mathrm{HA})$, respectively, and incubated for one hour at room temperature in a humid, light-tight box. The coverslips on which the cells were grown and fixed were mounted onto a microscope slide using Vectashield (Vector Laboratories; $\mathrm{H}-1000)$. The slides were imaged via Z-scan at $600 x$ magnification using an Olympus Fluoview FV1000 confocal microscope and the Olympus Fluoview 4.1 software. Following fluorescent microscopy, the images obtained were prepared and analyzed using the imaging software Adobe Illustrator, Fiji (Image J), and Vaa3d (Schindelin, 2012; Walter, 2010; Eliceiri, 2012; Peng, 2010; Peng, 2014). 


\section{Chapter 4: Results}

Overexpression of the canonical Wnt ligands Wnt3a and Wnt8 was not sufficient to induce TOP/FOP FLASH reporter activity (Figures 11 and 12). Overexpression of wild-type $\beta$-catenin ( $\beta$-cateninWT), however, was sufficient to induce TOP/FOP FLASH reporter activity (Figure 13). Co-expression of mouse ephrin-B1 $\triangle \mathrm{C}$ inhibited $\beta$ cateninWT - induced TOP/FOP FLASH reporter activity (Figure 14). Similarly, 24 hour $\mathrm{LiCl}$ treatment induced TOP/FOP FLASH reporter activity (Figure 15), and overexpression of mouse ephrin-B1 $\triangle \mathrm{C}$ abrogated the $\mathrm{LiCl}$ - induced TOP/FOP FLASH reporter activity (Figure 16). $\beta$-catenin* overexpression also induced TOP/FOP FLASH reporter activity (Figure 17 ). Co-expression with ephrin-B1 $\Delta \mathrm{C}$ abrogated the $\beta$-catenin* - induced TOP/FOP FLASH reporter activity (Figure 18).

Levels of total cellular $\beta$-catenin were deduced by calculating the adjusted relative density and the average and standard deviation of the adjusted relative density values of $\beta$-catenin under each treatment from three replicate Western blots. $\mathrm{LiCl}$ treatment results in an increase in total cellular $\beta$-catenin (Figures 19 and 20). Furthermore, overexpression of ephrin $\mathrm{B} 1 \Delta \mathrm{C}$ in the presence of $\mathrm{LiCl}$ treatment reduced the increase in total cellular $\beta$-catenin observed with $\mathrm{LiCl}$ alone (Figures 19 and 20). However, the increase in total cellular $\beta$-catenin upon $\mathrm{LiCl}$ treatment and the reduction of this effect with the addition of overexpression of ephrin-B1 $\Delta \mathrm{C}$, as measured by the adjusted relative density of $\alpha \beta$-catenin in Western blots, varied greatly among replicates (only one replicate is shown; Figure 19). Indeed, these results were not statistically significant, as revealed by t-test's.

Levels of total cellular E-cadherin were deduced by calculating the adjusted relative density values of E-cadherin under each treatment from two replicate Western blots (one replicate is shown; Figure 21). Total cellular E-cadherin increased in response to $\mathrm{LiCl}$ treatment Figure 21). Total cellular E-cadherin also increased in response to ephrin-B1 $\Delta \mathrm{C}$ overexpression (Figure 21). In one replicate Western blot for $\mathrm{E}$-cadherin, overexpression of ephrin-B1 $\Delta \mathrm{C}$ together with $\mathrm{LiCl}$ treatment did not affect the increase in total cellular E-cadherin observed in response to $\mathrm{LiCl}$ treatment alone (Figure 21) However, in another replicate Western blot for total cellular E-cadherin, 
overexpression of ephrin-B1 $\mathrm{C}$ together with $50 \mathrm{mM} \mathrm{LiCl}$ enhanced the observed increase in total cellular E-cadherin (data not shown). However, more experiments need to be performed to verify these effects.

Analysis of $\beta$-catenin subcellular localization using confocal immunofluorescence microscopy revealed that $\beta$-catenin subcellular localization varies in apical, middle, and basal Z-sections of HEK293T cells cultured to confluency (Figure 22). Membranelocalized $\beta$-catenin is very prominent at apical Z-sections, and is also apparent at basal Z-sections (Figure 22-25). Cytoplasmic $\beta$-catenin is observed in all Z-positions, however, cytoplasmic space is lacking in HEK293T cells, especially once they form cellcell interactions and become more tightly organized (Figure 22-25). Nuclear $\beta$-catenin is observed in some cells in the middle and apical Z-sections, and nuclear $\beta$-catenin punctae are observed in some cells in the apical Z-sections, particularly (Figure 22-25). $\mathrm{LiCl}$ treatment may enhance membrane localization of $\beta$-catenin at basal and, more prominently, apical Z-sections, and may enhance nuclear $\beta$-catenin punctae at apical Zsections (Figure 22-25). Overexpression of ephrinB1 $\Delta C$ also enhances membrane localization of $\beta$-catenin at basal and apical Z-sections, and the effect is even more prominent when $\mathrm{LiCl}$ treatment is applied in addition to overexpression of ephrin-B1 $\triangle \mathrm{C}$ (Figure 22-25).

SP600125 does not prevent inhibition of $\mathrm{LiCl}$ - induced TOP/FOP FLASH reporter expression by ephrin-B1 $\Delta C$ (Figure 26). Rather, SP600125 seems to enhance the ephrin-B1 $\triangle \mathrm{C}$ antagonism of $\mathrm{LiCl}$ - induced TOP/FOP FLASH reporter expression (Figure 26). 


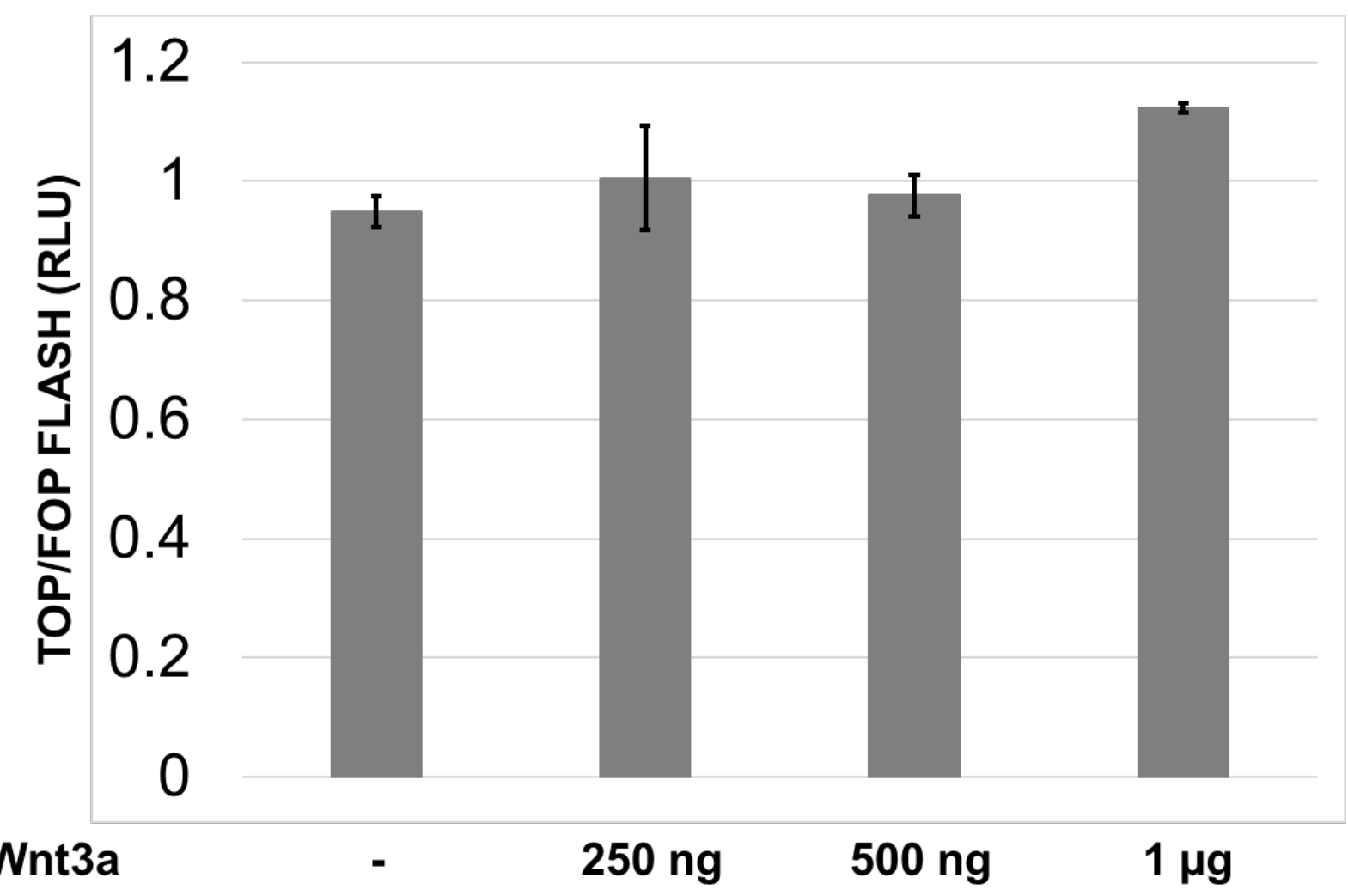

Figure 11: Wnt3a Overexpression is Not Sufficient to Induce Reporter Activity. HEK293T cells were grown at a controlled density for $\sim 24$ hours. The cells were transfected with pTOP FLASH (TOP) and pFOP FLASH (FOP) and the indicated constructs and cultured for $\sim 24$ hours. Cell lysates were processed for luciferase assays. A representative experiment performed in triplicate is shown here. Results are presented as average ratios of TOP vs. FOP luciferase activity measured as relative luminescence units $(R L U)$, and the error bars represent standard deviations. *: $P<0.05$, $\star \star: P<0.01,{ }^{\star \star \star} P<0.001$. 


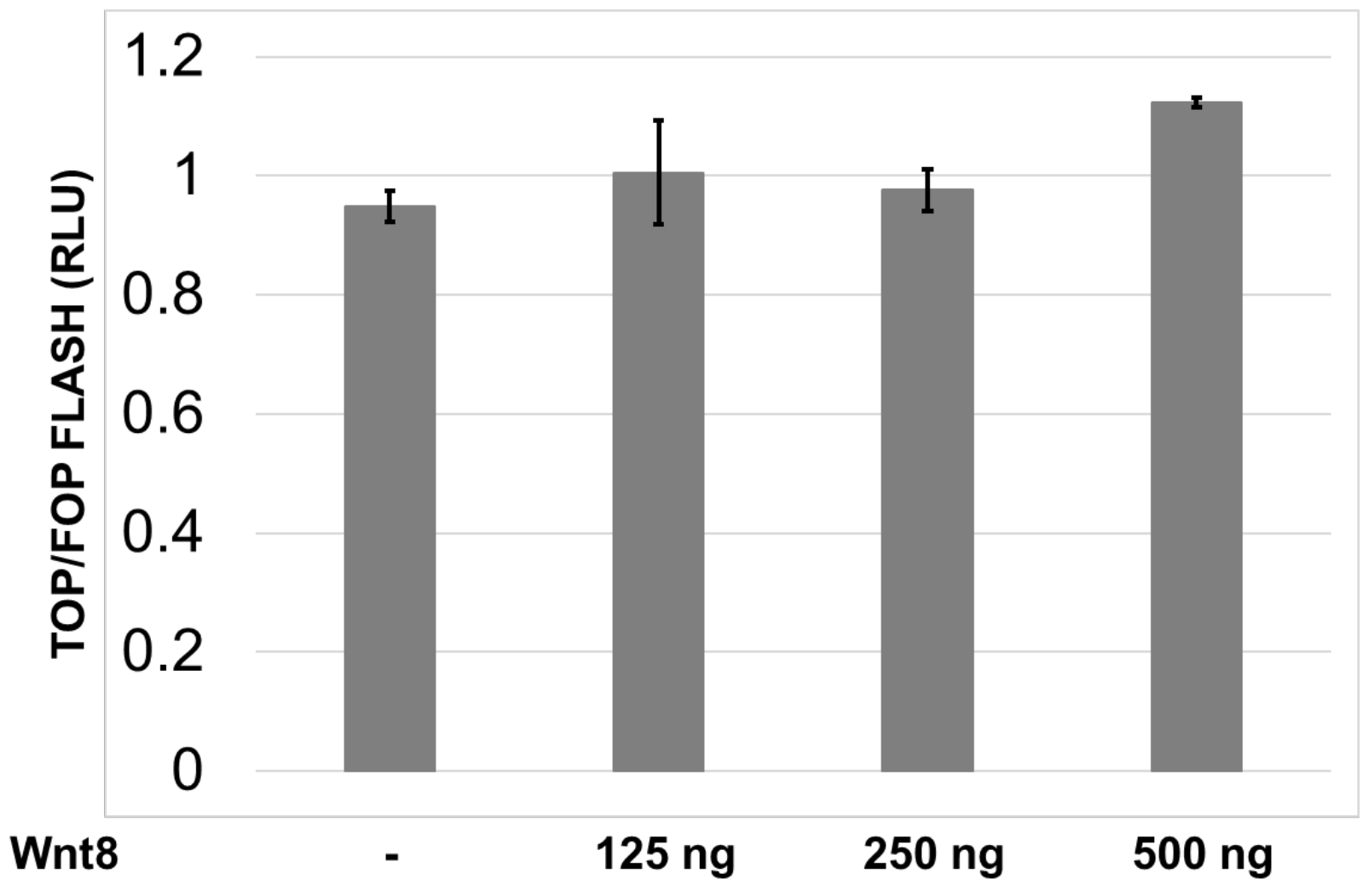

Figure 12: Wnt8 Overexpression is Not Sufficient to Induce Reporter Activity. HEK293T cells were grown at a controlled density for $\sim 24$ hours. The cells were transfected with pTOP FLASH (TOP) and pFOP FLASH (FOP) and the indicated constructs and cultured for $\sim 24$ hours. Cell lysates were processed for luciferase assays. A representative experiment performed in triplicate is shown here. Results are presented as average ratios of TOP vs. FOP luciferase activity measured as relative luminescence units $(R L U)$, and the error bars represent standard deviations. *: $P<0.05$, **: $P<0.01,{ }^{\star \star *} P<0.001$. 


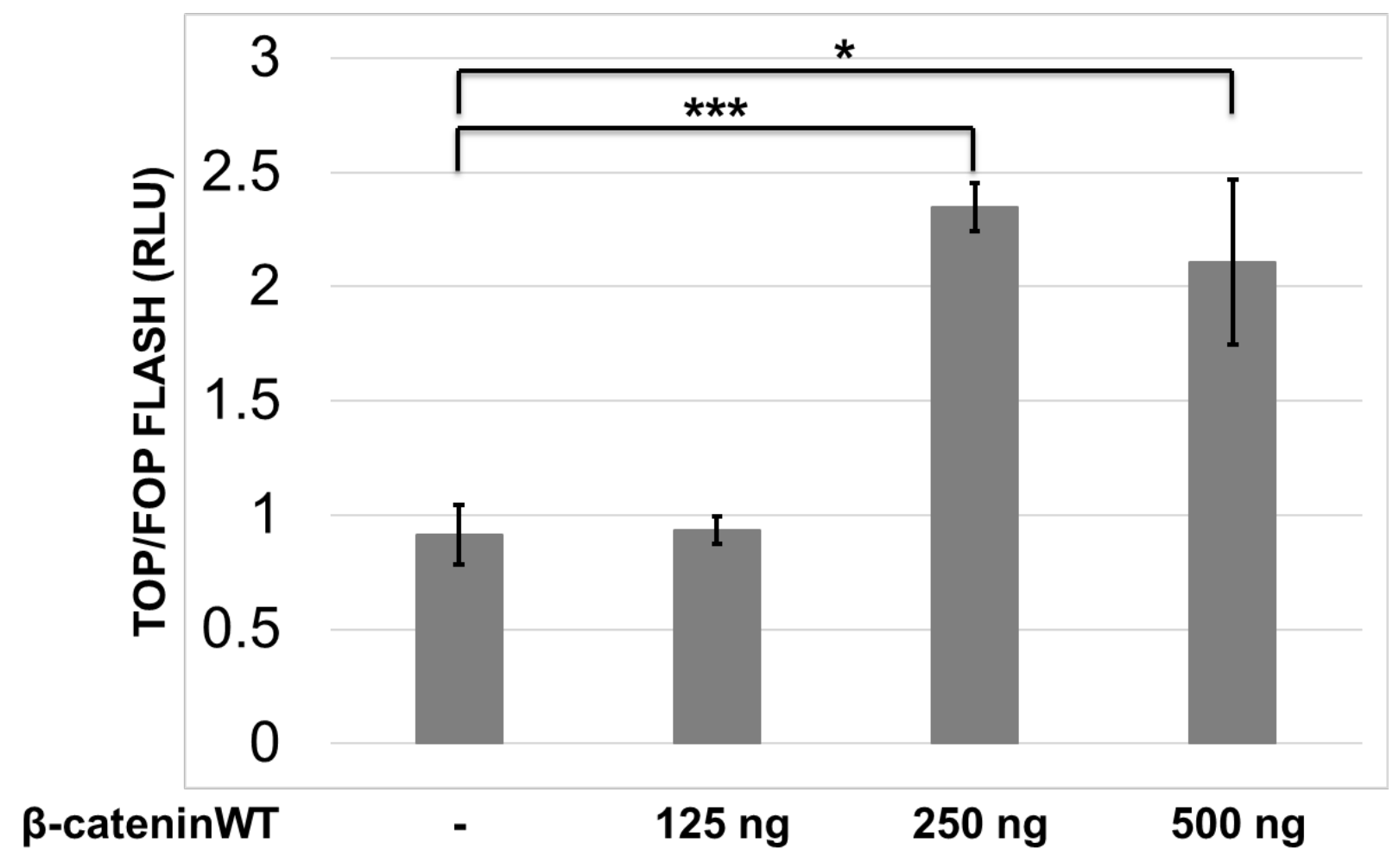

Figure 13: Wild-type $\beta$-catenin Overexpression Induces Reporter Activity. HEK293T cells were grown at a controlled density for $\sim 24$ hours. The cells were transfected with pTOP FLASH (TOP) and pFOP FLASH (FOP) and the indicated constructs and cultured for $\sim 24$ hours. Cell lysates were processed for luciferase assays. A representative experiment performed in triplicate is shown here. Results are presented as average ratios of TOP vs. FOP luciferase activity measured as relative luminescence units $(R L U)$, and the error bars represent standard deviations. *: $P<0.05$, **: $\mathrm{P}<0.01,{ }^{* \star *} \mathrm{P}<0.001$. 


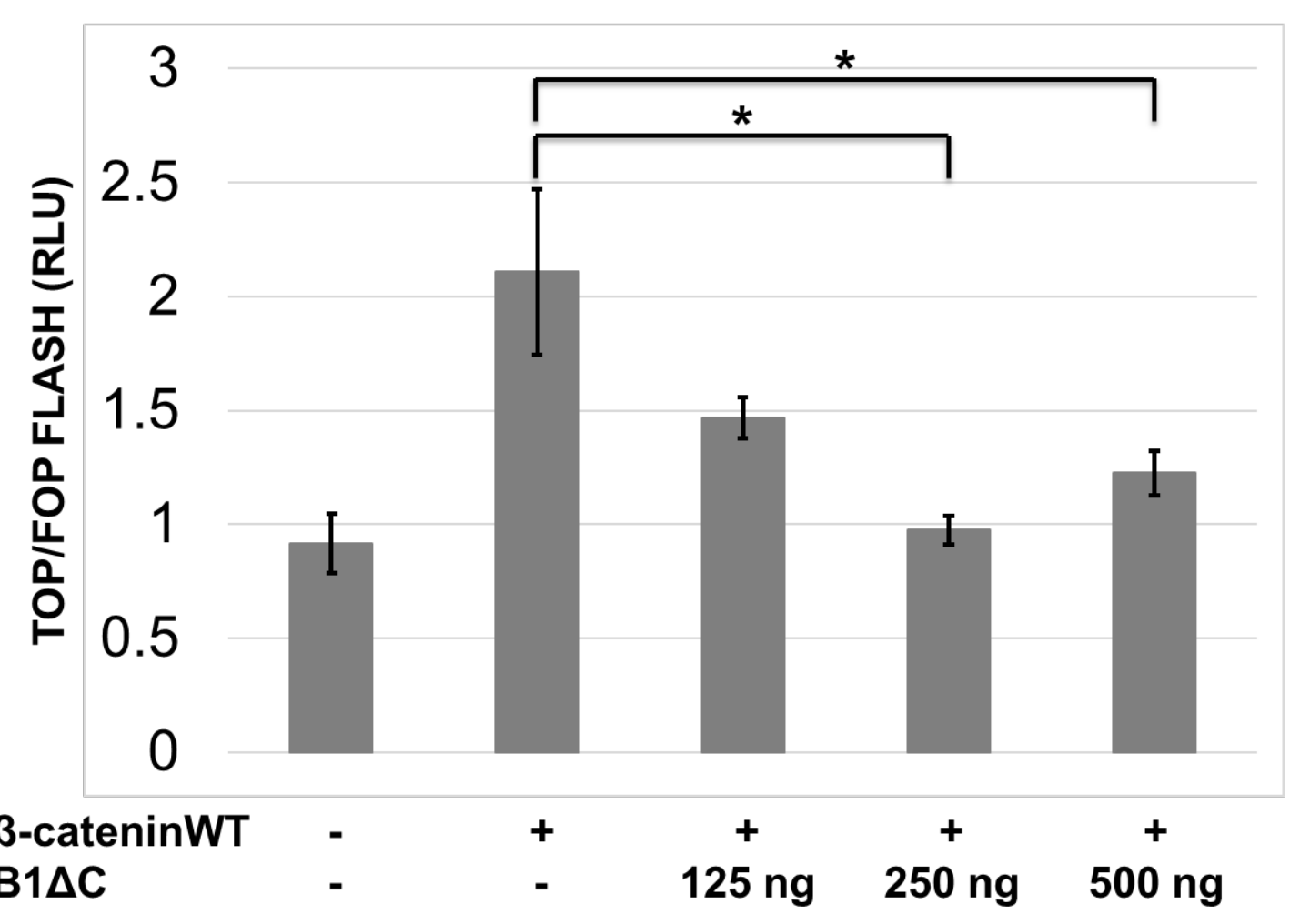

Figure 14: ephrin-B1 $\Delta C$ Inhibits Wild-type $\beta$-catenin - Induced Reporter Activity. HEK293T cells were grown at a controlled density for $\sim 24$ hours. The cells were transfected with pTOP FLASH (TOP) and pFOP FLASH (FOP) and the indicated constructs and cultured for $\sim 24$ hours. Cell lysates were processed for luciferase assays. A representative experiment performed in triplicate is shown here. Results are presented as average ratios of TOP vs. FOP luciferase activity measured as relative luminescence units (RLU), and the error bars represent standard deviations. *: $P<0.05$, **: $\mathrm{P}<0.01,{ }^{* * *} \mathrm{P}<0.001$. 


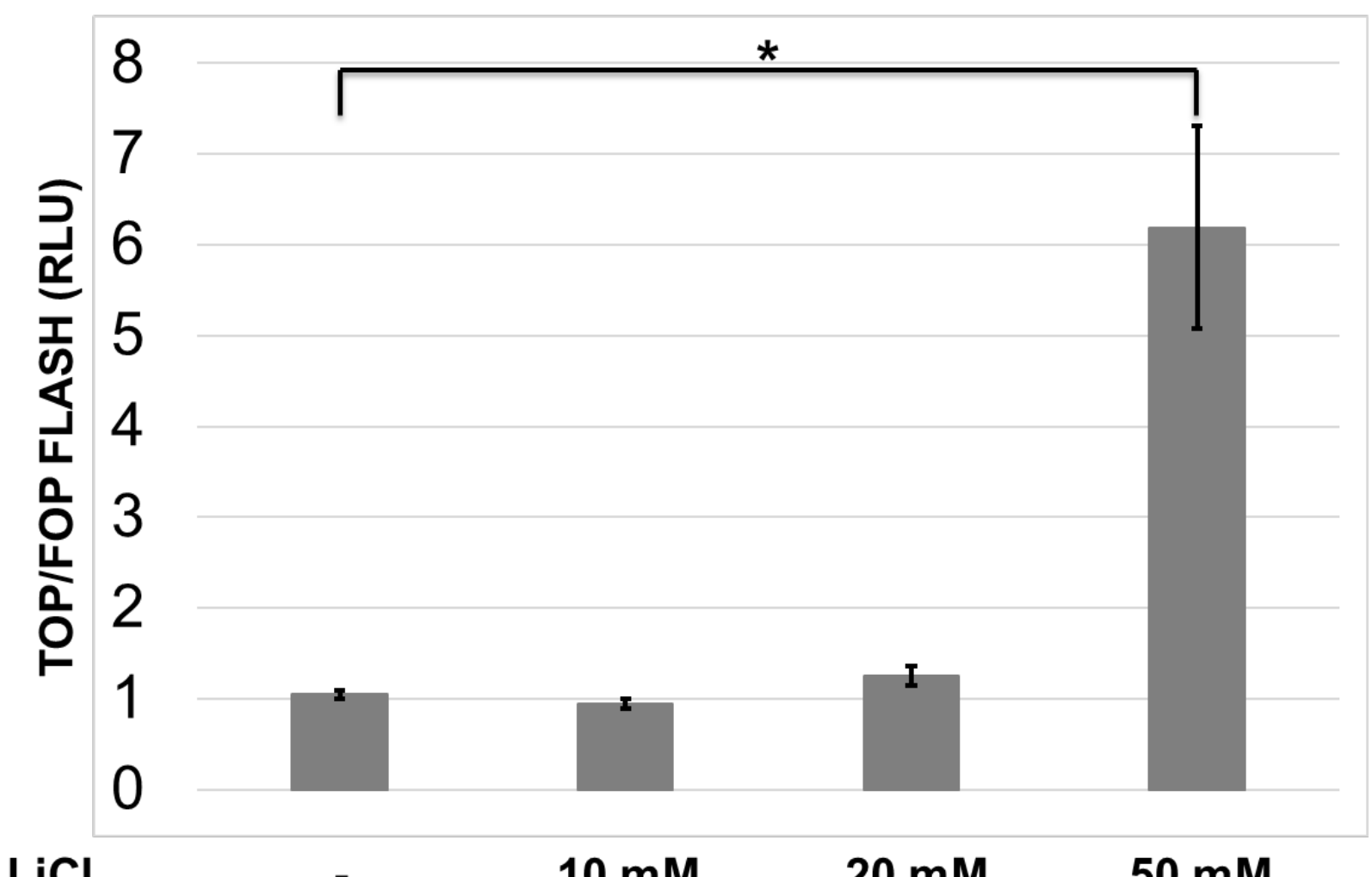

Figure 15: LiCl Induces Reporter Activity. HEK293T cells were grown at a controlled density for $\sim 24$ hours. The cells were treated with $50 \mathrm{mM} \mathrm{LiCl}$, transfected with pTOP FLASH (TOP) and pFOP FLASH (FOP) and the indicated constructs, and cultured for $\sim 24$ hours. Cell lysates were processed for luciferase assays. A representative experiment performed in triplicate is shown here. Results are presented as average ratios of TOP vs. FOP luciferase activity measured as relative luminescence units $(R L U)$, and the error bars represent standard deviations. *: $P<0.05,{ }^{\star *}: P<0.01,{ }^{* \star *} P$ $<0.001$. 


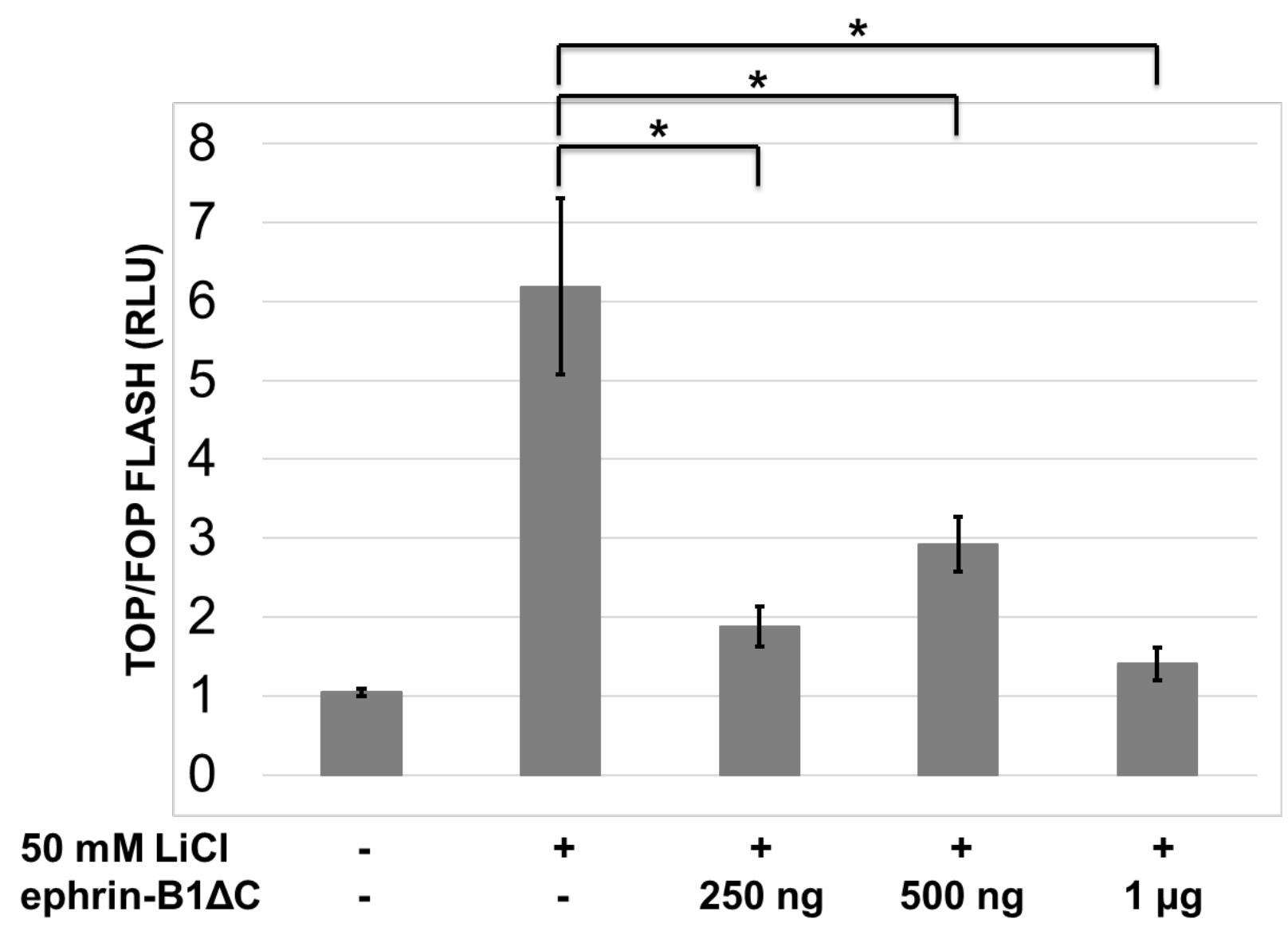

Figure 16: ephrin-B1 $\Delta$ C Inhibits LiCl - Induced Reporter Activity. HEK293T cells were grown at a controlled density for $\sim 24$ hours. The cells were treated with $50 \mathrm{mM}$ $\mathrm{LiCl}$, transfected with pTOP FLASH (TOP) and pFOP FLASH (FOP) and the indicated constructs, and cultured for $\sim 24$ hours. Cell lysates were processed for luciferase assays. A representative experiment performed in triplicate is shown here. Results are presented as average ratios of TOP vs. FOP luciferase activity measured as relative luminescence units $(R L U)$, and the error bars represent standard deviations. *: $P<0.05$, **: $\mathrm{P}<0.01,{ }^{* * *} \mathrm{P}<0.001$. 


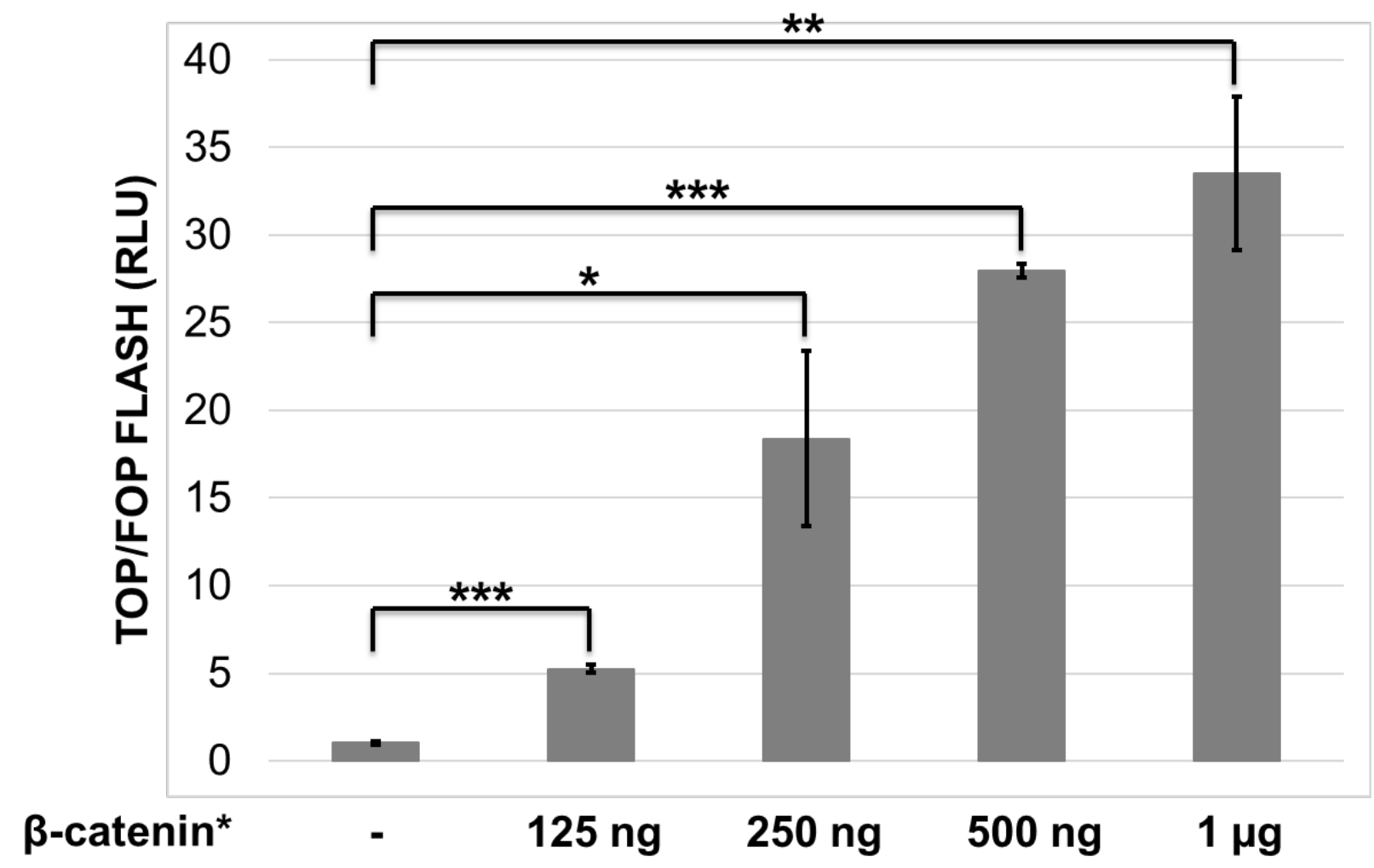

Figure 17: $\boldsymbol{\beta}$-catenin* Overexpression Induces Reporter Activity. HEK293T cells were grown at a controlled density for $\sim 24$ hours. The cells were transfected with pTOP FLASH (TOP) and pFOP FLASH (FOP) and the indicated constructs and cultured for $\sim 24$ hours. Cell lysates were processed for luciferase assays. A representative experiment performed in triplicate is shown here. Results are presented as average ratios of TOP vs. FOP luciferase activity measured as relative luminescence units $(R L U)$, and the error bars represent standard deviations. ${ }^{*}: P<0.05,{ }^{\star *}: P<0.01,{ }^{\star} * \star P$ $<0.001$. 


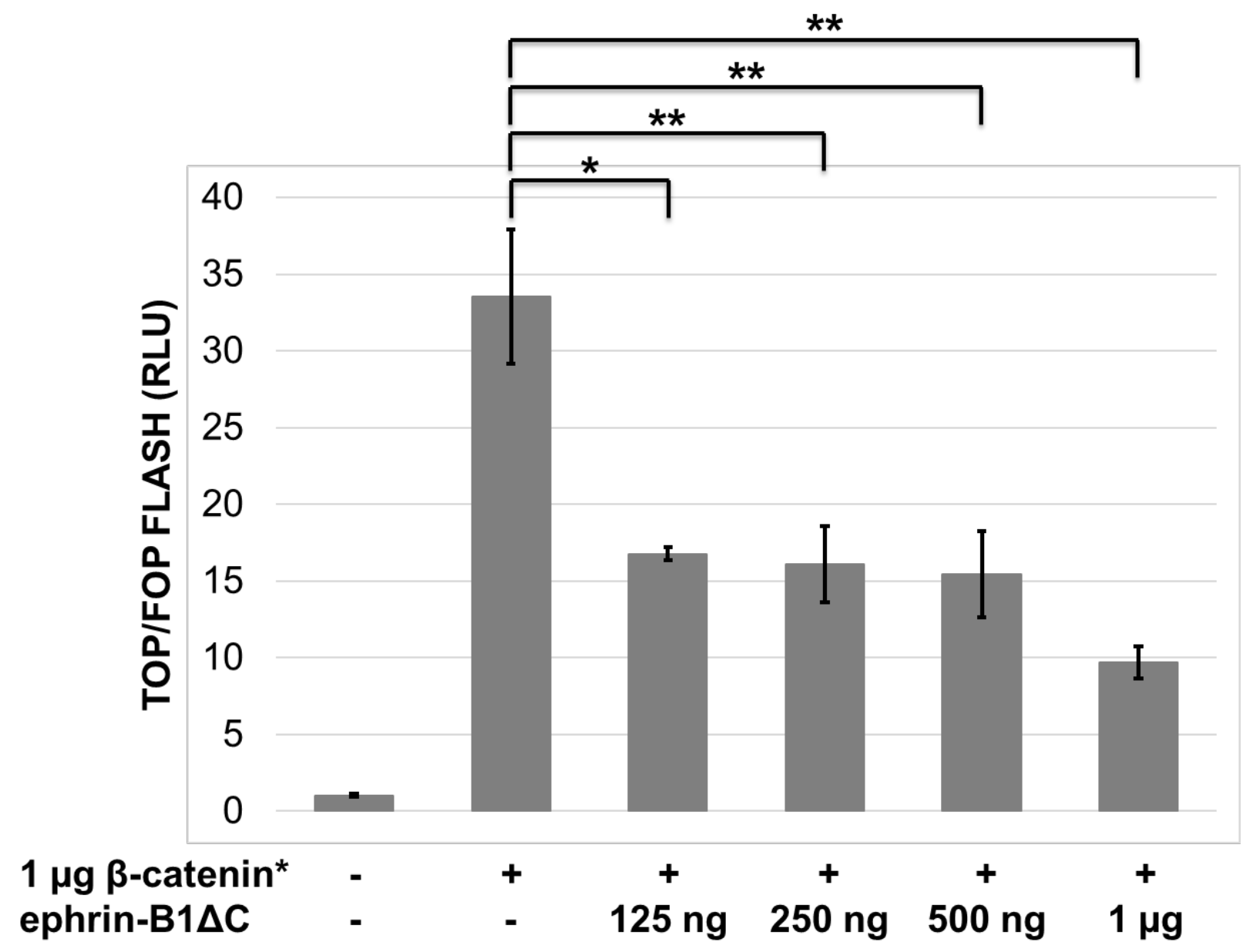

Figure 18: ephrin-B1 $\Delta C$ Inhibits $\beta$-catenin* - Induced Reporter Activity. HEK293T cells were grown at a controlled density for $\sim 24$ hours. The cells were transfected with pTOP FLASH (TOP) and pFOP FLASH (FOP) and the indicated constructs and cultured for $\sim 24$ hours. Cell lysates were processed for luciferase assays. A representative experiment performed in triplicate is shown here. Results are presented as average ratios of TOP vs. FOP luciferase activity measured as relative luminescence units $(R L U)$, and the error bars represent standard deviations. *: $\mathrm{P}<0.05,{ }^{* *}: \mathrm{P}<0.01,{ }^{* * *} \mathrm{P}$ $<0.001$. 

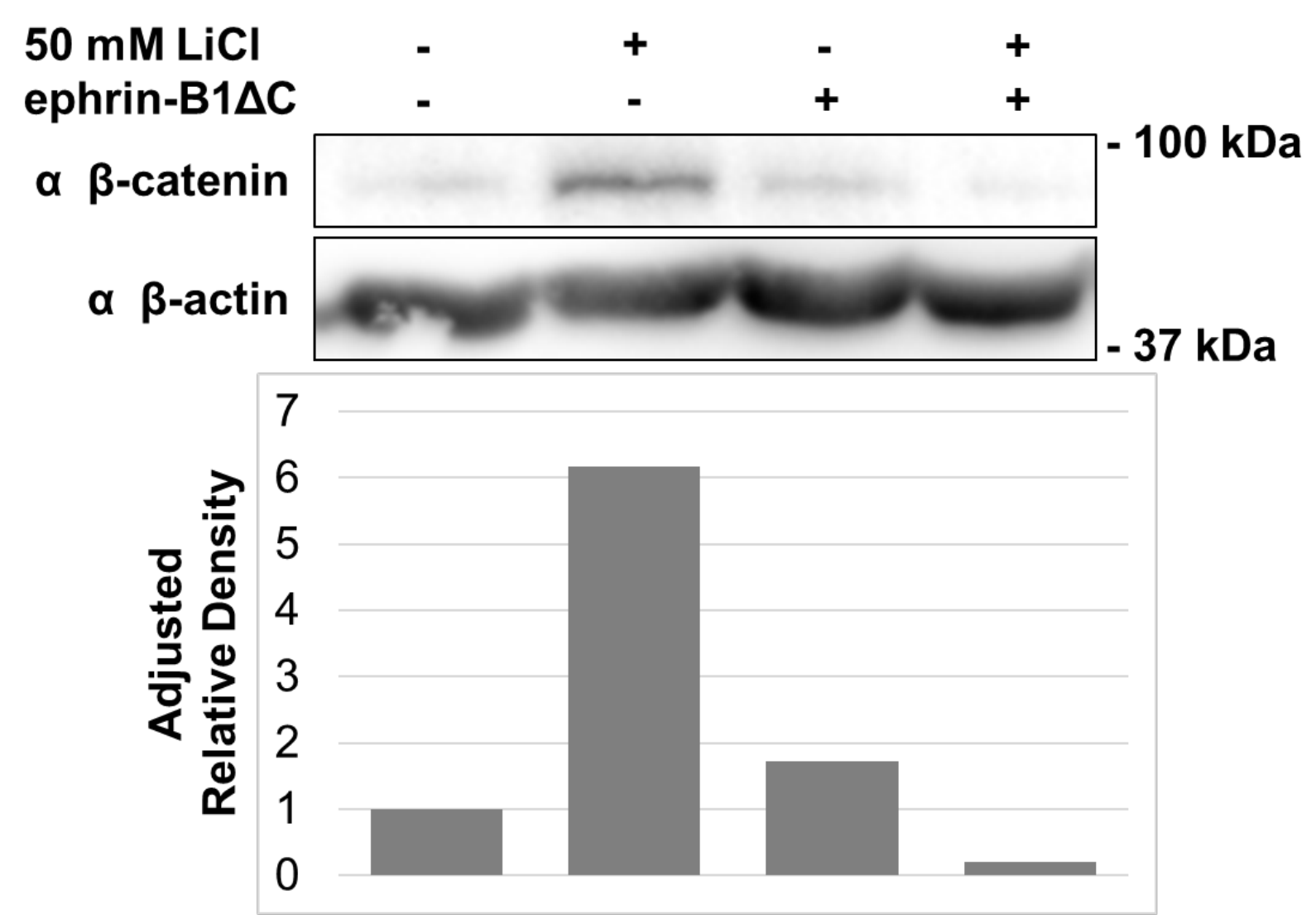

Figure 19: ephrin-B Signaling Affects Levels of Total Cellular $\boldsymbol{\beta}$-catenin. HEK293T cells were grown at a controlled density for $\sim 24$ hours. The cells were treated with 50 $\mathrm{mM} \mathrm{LiCl}$, transfected with pTOP FLASH (TOP) and pFOP FLASH (FOP) and the indicated constructs, and cultured for $\sim 24$ hours. Western blots of whole cell lysates were carried out using $\alpha \beta$-catenin. The Western blots were stripped and blotted for $\alpha \beta$ actin. The adjusted relative density of each $\beta$-catenin band was calculated using Fiji, and normalized (to obtain the adjusted relative density) for the relative amount of cell lysate by dividing the integrated density of each $\beta$-catenin band by the respective integrated density of the respective $\beta$-actin band and setting the adjusted relative density of the negative control group to 1 . 


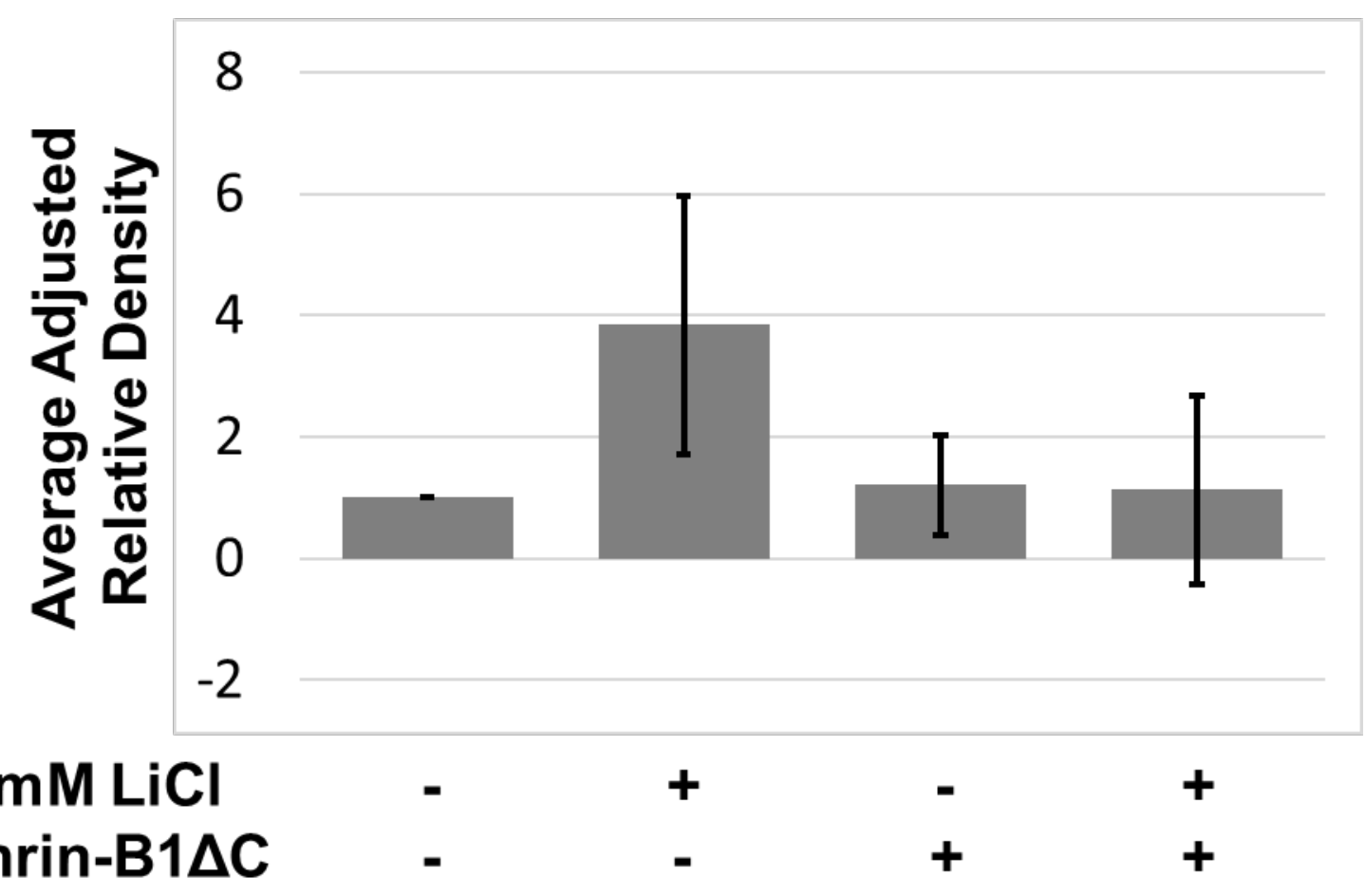

Figure 20: ephrin-B Signaling Affects Levels of Total Cellular $\beta$-catenin. The averages and standard deviations of the adjusted relative densities of $\alpha \beta$-catenin from three Western blots of cell lysates from three biological replicates of each treatment performed in parallel was calculated. 

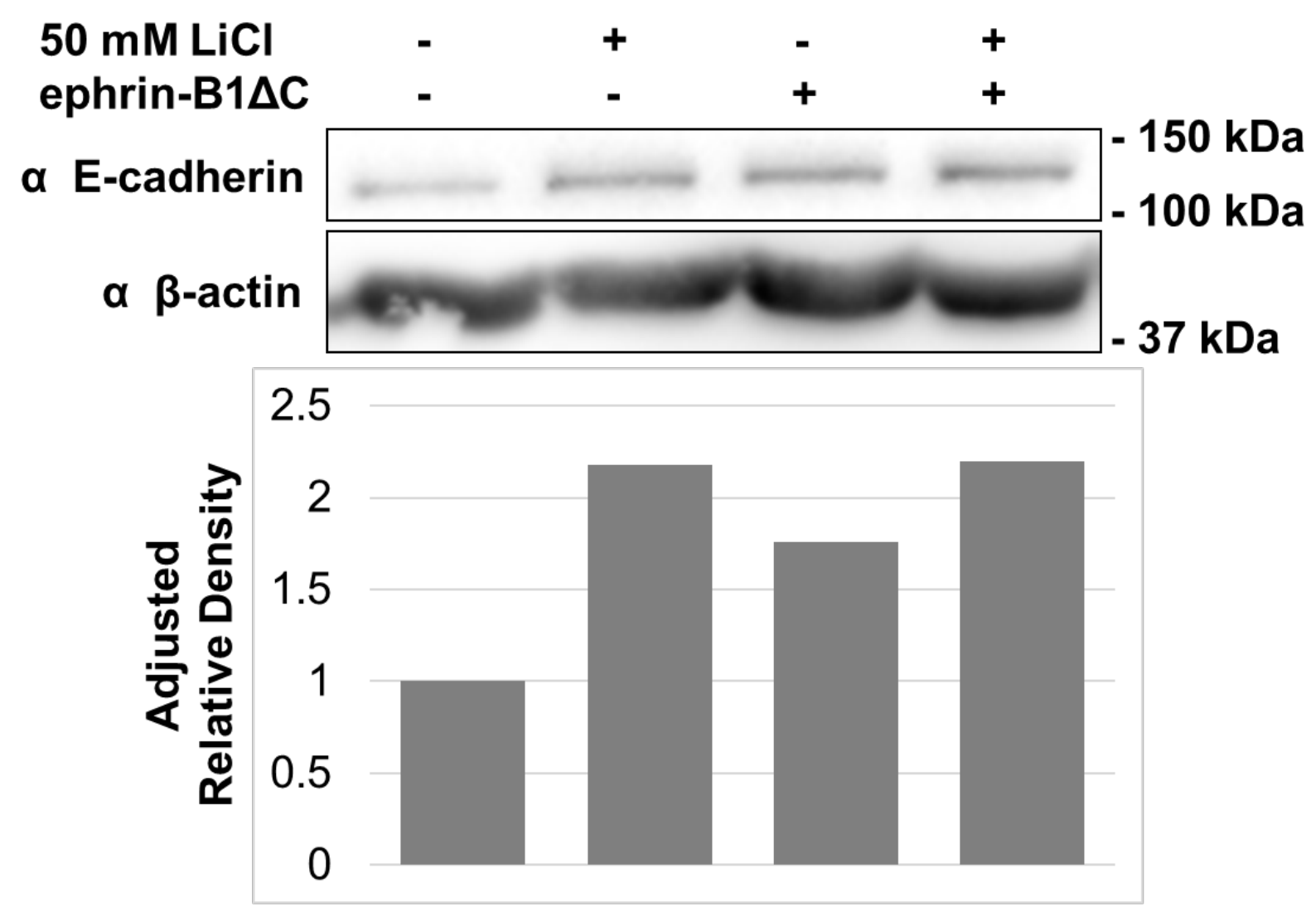

Figure 21: LiCl and ephrin-B Signaling Increase Levels of Total Cellular E-cadherin Independently and Co-Treatment Does Not Influence this Effect. HEK293T cells were grown at a controlled density for $\sim 24$ hours. The cells were treated with $50 \mathrm{mM} \mathrm{LiCl}$, transfected with pTOP FLASH (TOP) and pFOP FLASH (FOP) and the indicated constructs, and cultured for $\sim 24$ hours. Two of the Western blots of whole cell lysates blotted for $\alpha \beta$-catenin and $\alpha \beta$-actin were re-stripped and blotted for $\alpha \mathrm{E}$ cadherin (hence, $\alpha \beta$-actin image is reproduced from Figure 19), and one of these Western blots is shown. The adjusted relative density of each $\beta$-catenin band was calculated using Fiji, and normalized (to obtain the adjusted relative density) for the relative amount of cell lysate by dividing the integrated density of each $\beta$-catenin band by the respective integrated density of the respective $\beta$-actin band and setting the adjusted relative density of the negative control group to 1 . 


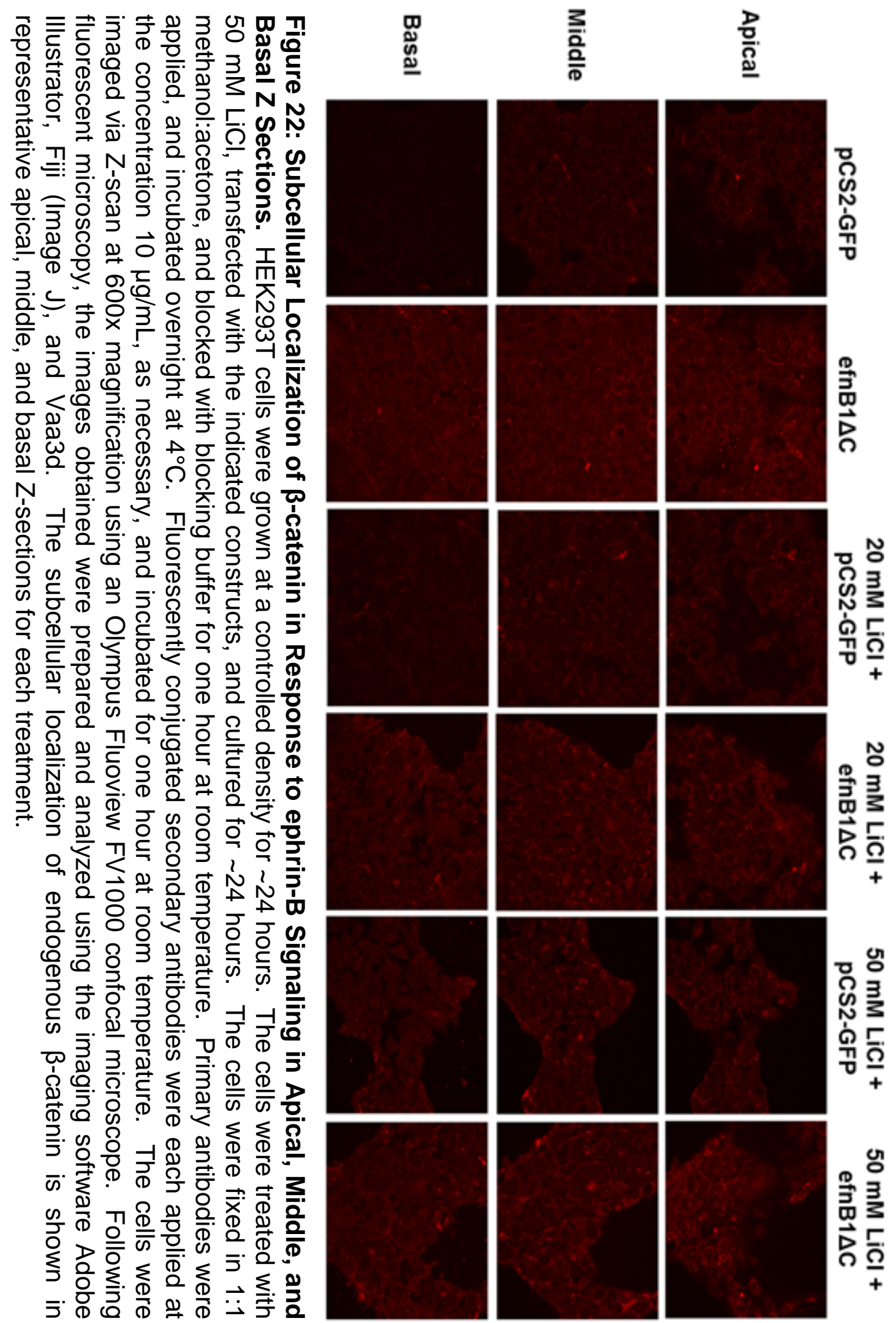




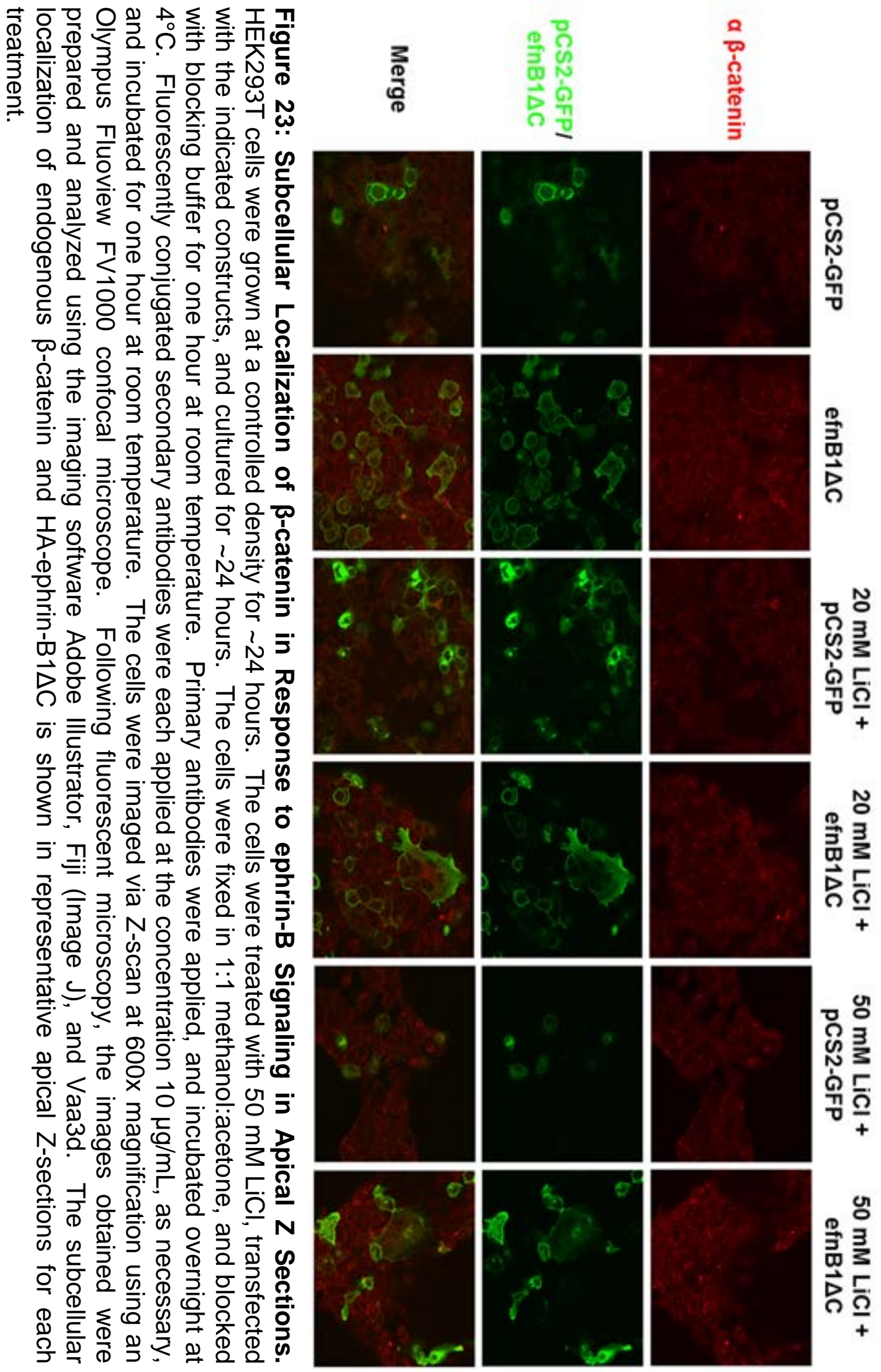




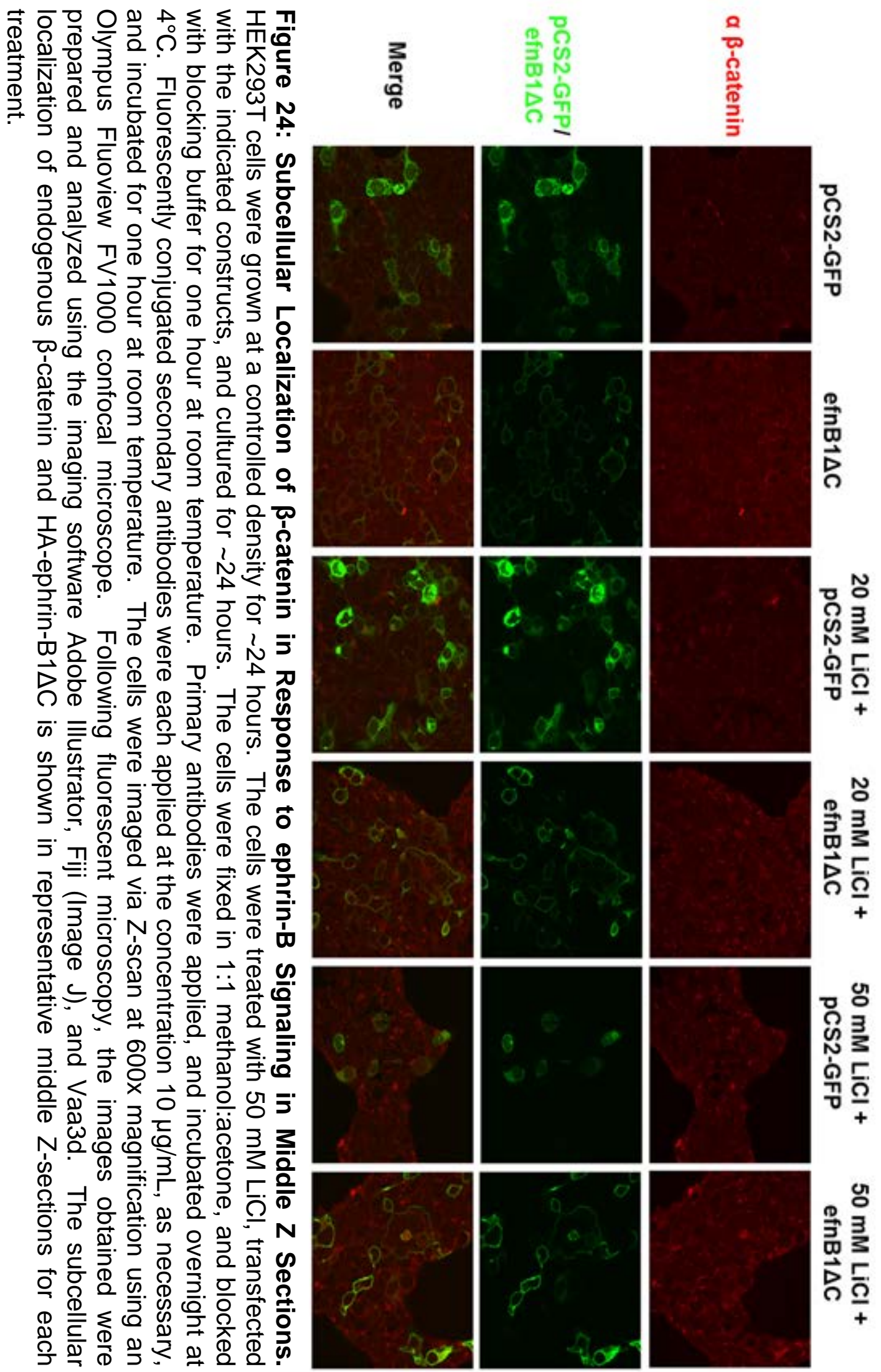




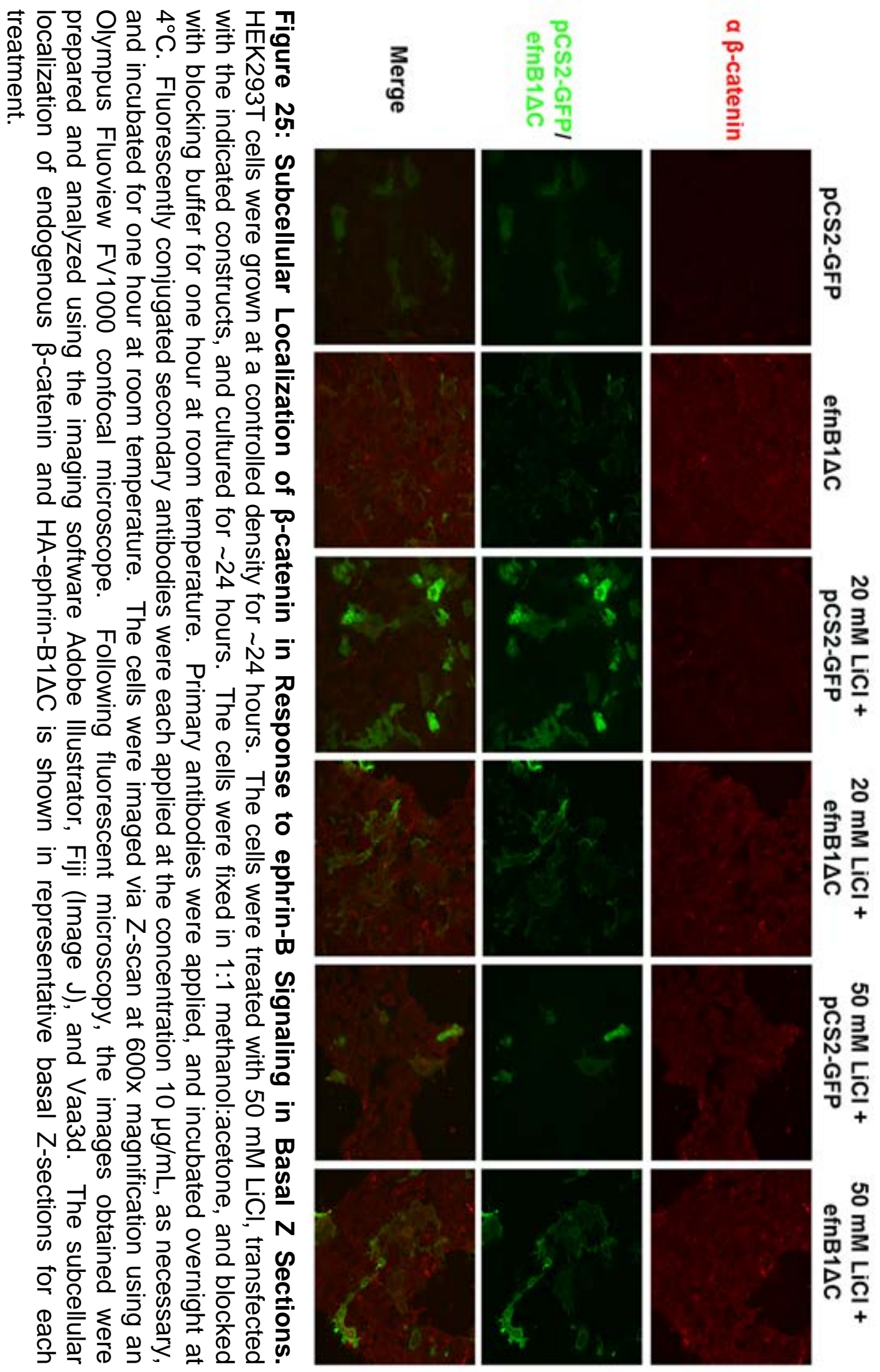




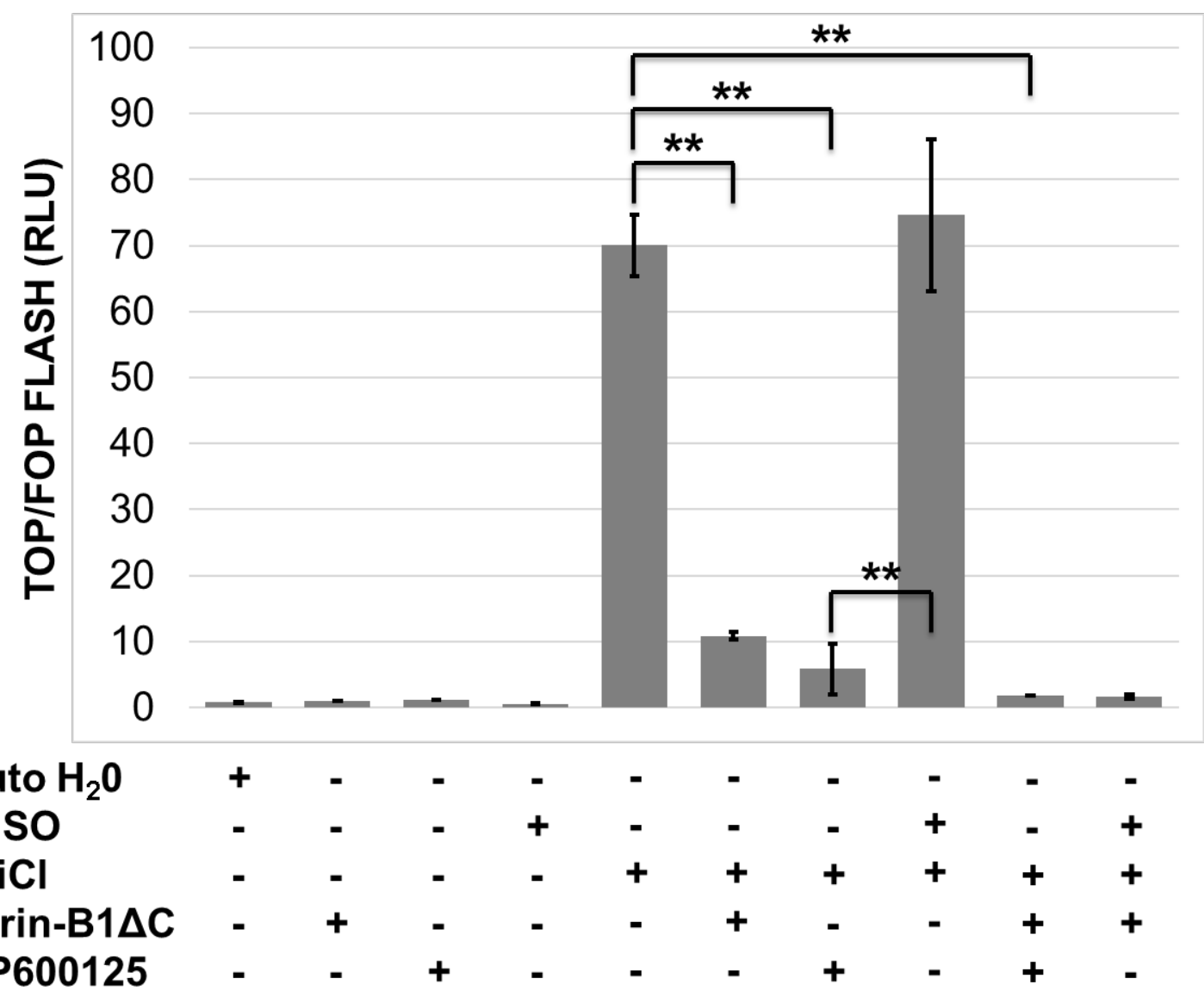

Figure 26: Inhibition of c-Jun N-terminal kinase (JNK) Inhibits $\mathrm{LiCl}$ - Induced Reporter Activity and Enhances the ephrin-B1 $\Delta \mathrm{C}$ Inhibition of LiCl - Induced Reporter Activity. HEK293T cells were grown at a controlled density for $\sim 24$ hours. $50 \mu \mathrm{M}$ SP600125 (pan-JNK inhibitor), 0.1\% DMSO (vehicle control for SP600125), or $0.01 \%$ auto $\mathrm{H}_{2} \mathrm{O}$ (vehicle control for $\mathrm{LiCl}$ ) were added to fresh DMEM, and the media of the cells was replaced as necessary. The cells were treated with $50 \mathrm{mM} \mathrm{LiCl}$, transfected with pTOP FLASH (TOP) and pFOP FLASH (FOP) and the indicated constructs, and cultured for $\sim 24$ hours. Cell lysates were processed for luciferase assays. A representative experiment performed in triplicate is shown here. Results are presented as average ratios of TOP vs. FOP luciferase activity measured as relative luminescence units $(R L U)$, and the error bars represent standard deviations. *: $P<0.05$, **: $\mathrm{P}<0.01,{ }^{* \star *} \mathrm{P}<0.001$. 


\section{Chapter 5: Discussion}

As described earlier, the ephrin-B antagonism of canonical Wnt signaling was initially suggested in a TOP/FOP FLASH assay in HEK293T cells using Xenopus ephrin-B1 and ephrin-B1 $\triangle \mathrm{C}$. Therefore, we aimed to validate this novel interaction using a TOP/FOP FLASH assay in HEK293T cells using Mus musculus constructs in order to determine if this interaction is evolutionarily conserved in mammals. Overexpression of mammalian ephrin-B1 $\Delta C$ in HEK293T cells inhibits TOP/FOP FLASH reporter activity induced by the application of $\mathrm{LiCl}$, and overexpression of mammalian WT $\beta$-catenin and $\beta$-catenin* (Figures 16,14 , and 18 ). These results suggest that the ephrin-B antagonism of canonical Wnt signaling is evolutionarily conserved between amphibians and mammals.

Because ephrin-Bs can mediate both forward and reverse signaling, we employed two ephrin-B constructs to determine whether forward or reverse ephrin-B signaling is responsible for the ephrin-B mediated antagonism of canonical Wnt signaling. Ephrin-B1 mediates both forward and reverse signaling, while ephrin-B1 $\triangle C$ mediates forward signaling, and when overexpressed, can dominant-negatively inhibit reverse signaling. Because ephrin-B1 and ephrin-B1 $\triangle \mathrm{C}$ had similar effects on $\mathrm{LiCl}, \beta$ cateninWT, and $\beta$-catenin* - induced TOP/FOP FLASH reporter activity, we propose that the ephrin-B antagonism of canonical Wnt signaling in HEK293T cells is likely relies on forward, rather than reverse, ephrin-B signaling (Figures 16, 14, and 18; ephrin-B1 data: Perfetto et al. unpublished data).

Due to the central role of $\beta$-catenin in canonical Wnt signaling, we hypothesized that the ephrin-B antagonism of canonical Wnt signaling likely involves an alteration of the stability and/or subcellular localization of $\beta$-catenin. To determine whether the ephrin-B antagonism of canonical Wnt signaling is dependent on the destruction complex-mediated degradation of $\beta$-catenin, we employed $\mathrm{LiCl}$, which activates canonical Wnt signaling by inhibiting GSK3 $\beta$, thereby preventing the degradation of $\beta$ catenin whether it is newly synthesized $\beta$-catenin or $\beta$-catenin released from other interactors. We also employed a $\beta$-catenin mutant described previously, $\beta$-catenin* that has mutations in the GSK3 $\beta$-targeted sites and hence cannot be modified by the 
destruction complex. Overexpression of ephrin-B1 $\Delta \mathrm{C}$ inhibits LiCl-induced TOP/FOP FLASH activity in HEK293T cells (Figure 16). Similarly, overexpression of ephrin-B1 $\triangle \mathrm{C}$ inhibits $\beta$-catenin* - induced TOP/FOP FLASH activity in HEK293T cells (Figure 18). Taken together, these results suggest that the ephrin-B can antagonize canonical Wnt signaling independently of the $\beta$-catenin destruction complex, and likely inhibits canonical Wnt signaling downstream of the destruction complex. However, we cannot rule out additional effects upstream or at the level of regulation of $\beta$-catenin stability via GSK3 $\beta$ and the $\beta$-catenin destruction complex. In line with this latter hypothesis, Western blots for $\beta$-catenin indicate that the ephrin-B antagonism of canonical Wnt signaling may involve a reduction in total cellular $\beta$-catenin levels (Figures 19 and 20).

We employed immunofluorescence microscopy to investigate the effects of ephrin-B signaling on the subcellular localization of $\beta$-catenin. As shown in 22-25, ephrin-B signaling may affect $\beta$-catenin subcellular localization, increasing the relative amount of $\beta$-catenin at the cell membrane. Because total cellular $\beta$-catenin is distributed among membrane-bound, cytosolic and nuclear pools, an increase in the membrane-bound pool may result in reduction of the nuclear pool of $\beta$-catenin, which is the only fraction that is functional in mediating canonical Wnt signaling. To further test this hypothesis, we are in the process of quantifying functional $\beta$-catenin in HEK293T cells with and without ectopic ephrin-B1 $\Delta \mathrm{C}$ by purifying nuclear proteins from the cell lysates.

JNK is activated downstream of ephrin-B signaling and JNK 1 and 2 directly interact with and phosphorylate $\beta$-catenin. However, there are conflicting reports regarding the result of the JNK-phosphorylation of $\beta$-catenin (Hu, 2008; Hu, 2009; Liao, 2006; Wu, 2008). In addition, JNK 1 and 2- phosphorylation of $\beta$-catenin may have opposite effects. We confirmed that JNK is activated in response to ephrin-B signaling in HEK293T cells using a JNK Assay Kit (Figure 9). Furthermore, we employed the pan-JNK inhibitor, SP600125, to determine if JNK activity is required for the ephrin-B antagonism of canonical Wnt signaling. As shown in Figure 26, inhibition of JNK using SP600125 does not prevent the ephrin-B - mediated inhibition of $\mathrm{LiCl}$ or $\beta$-catenin* - induced TOP/FOP FLASH activity, but rather seems to enhance the effect (Figure 26). In 
addition, inhibition of JNK alone inhibits $\mathrm{LiCl}$ - induced TOP/FOP FLASH activity (Figure 26). This result is consistent with reports that JNK-phosphorylation of $\beta$-catenin results in nuclear accumulation of $\beta$-catenin, and activates canonical Wnt signaling in HEK293T cells (Wu, 2008). Future efforts will be focused on testing if other effectors of forward ephrin-B signaling, such as RhoA and Rac1, contribute to the inhibition of canonical Wnt signaling. 


\section{Works Cited:}

Abiola et al. Activation of Wnt/B-catenin signaling increases insulin sensitivity through reciprocal regulation of Wnt10b and SREBP-1c in skeletal muscle cells. PLOS ONE (2009) 4(12): e8509.

Alexander et al. Wnt signaling interacts with Bmp and Edn1 to regulate dorsal-ventral patterning and growth of the craniofacial skeleton. PLoS Genetics (2014) 10(7): e1004479.

Aman, A., and Piotrowski, T. Wnt/ß-catenin and Fgf signaling control collective cell migration by restricting chemokine receptor expression. Developmental Cell (2008) 15: 749-761.

Bai, G., \& Pfaff, S.L. Protease regulation: the Yin and Yang of neural development and disease. Neuron (2011) 72(1): 9-21.

Batlle, E. Wnt signaling and EphB-ephrin interactions in intestinal stem cells and colorectal cancer progression. IRB Barcelona. Scientific Report: Oncology Programme (2007) [Internet] Retrieved April 22, 2016, from http://www.irbbarcelona.org/files/File/023-wnts-07.pdf.

Baron, R. and Kneissel, M. Wnt signaling in bone homeostasis and disease: from human mutations to treatments. Nature Medicine (2013) 19(2): 179-192.

Behrens et al. Functional interaction of $\beta$-catenin with the transcription factor LEF-1. Nature (1996) 382: 638-642.

Bennett et al. SP600125, an anthrapyrazolone inhibitor of Jun N-terminal kinase. PNAS (2001) 98(24): 13681-13686.

Beta-catenin-ARM-domain-interactions.png. [Internet] Retrieved April 21, 2016, from https://commons.wikimedia.org/wiki/File\%3ABeta-catenin-ARM-domaininteractions.png By Bubus12 (Own work) [CC BY 3.0 license], via Wikimedia Commons.

Bhanot et al. A new member of the frizzled family from Drosophila functions as a Wingless receptor. Nature (1996) 382(6588):225-230.

Bienz, M., and Clevers, H. Linking colorectal cancer to Wnt signaling. Cell (2000) 103: 311-320.

Brack et al. BCL9 is an essential component of canonical Wnt signaling that mediates the differentiation of myogenic progenitors during muscle regeneration. Developmental Biology (2009) 335(1): 93-105. 
Brembeck et al. Essential role of BCL9-2 in the switch between $\beta$-catenin's adhesive and transcriptional functions. Genes and Development (2004) 18: 2225-2230.

Buikema et al. Wnt/ $\beta$-catenin signaling during cardiac development and repair. Journal of Cardiovascular Development and Disease (2014) 1: 98-110.

Cadigan, K.M. and Waterman, M.L. TCF/LEFs and Wnt signaling in the nucleus. Cold Spring Harbor Perspectives in Biology (2012) 4: a007906.

Cao et al Nuclear-cytoplasmic shuttling of menin regulates nuclear translocation of $\beta$ catenin. Molecular and Cellular Biology (2009) 29(20): 5477-5487.

Chen et al. Dishevelled 2 recruits $ß$-arrestin 2 to mediate Wnt5A-stimulated endocytosis of Frizzled 4. Science (2003) 301(5638): 1391-1394.

Chen et al. Functional significance of type 1 insulin-like growth factor-mediated nuclear translocation of the insulin receptor substrate- 1 and $\beta$-catenin. Journal of Biological Chemistry (2005) 280: 29912-29920.

Chiu et al. Over-expression of EphB3 enhances cell-cell contacts and suppresses tumor growth in HT-29 human colon cancer cells. Carcinogenesis (2009) 30(9): 14751486.

Clevers, H. Wnt/ $\beta$-catenin signaling in development and disease. Cell (2006a) 127: 469480.

Clevers, H., and Batlle, E. EphB/EphrinB receptors and Wnt signaling in colorectal cancer. Cancer Research (2006b) 66(1): 2-5.

Clevers, H. and Nusse, R. Wnt/ß-catenin signaling and disease. Cell (2012) 149: 11921205. Available from: http://dx.doi.org/10.1016/j.cell.2012.05.012.

Clevers, H., Loh, K.M., and Nusse, R. An integral program for tissue renewal and regeneration: Wnt signaling and stem cell control. Science (2014) 346(6205): 17.

Conacci-Sorrell et al. Autoregulation of E-cadherin expression by cadherin-cadherin interactions: the roles of $\beta$-catenin signaling, Slug, and MAPK. The Journal of Cell Biology (2003) 163(4): 847-857.

Cong, F., Varmus, H. Nuclear-cytoplasmic shuttling of Axin regulates subcellular localization of $\beta$-catenin. PNAS (2004) 101:2882- 2887.

Cruciat, C. M., \& Niehrs, C. Secreted and transmembrane Wnt inhibitors and activators. Cold Spring Harbor Perspectives in Biology (2013) 5(3): a015081. 
Damsky et al. $\beta$-catenin signaling controls metastasis in Braf-activated Pten-deficient melanomas. Cancer Cell (2011) 20: 741-754.

Daniels, D.L., and Weis, W.I. $\beta$-catenin directly displaces Groucho/TLE repressors from Tcf/Lef in Wnt-mediated transcription activation. Nature Structural \& Molecular Biology (2005) 12(4): 364-371.

de Lau, W., Barker, N., and Clevers, H. Wnt signaling in the normal intestine and colorectal cancer. Frontiers in Bioscience (2007) 12:471-491.

Eleftheriou, A., Yoshida, M., and Henderson, B.R. Nuclear export of human $\beta$-catenin can occur independent of CRM1 and the adenomatous polyposis coli tumor suppressor. The Journal of Biological Chemistry (2001) 276(28): 25883-25888.

Eliceiri et al. Biological imaging software tools. Nature Methods (2012) 9(7): 697-710.

Elkouby, Y. M., \& Frank, D. Wnt/ $\beta$-catenin signaling in vertebrate posterior neural development. Colloquium Series on Developmental Biology (2010) 1(1): p. 1-79. Morgan \& Claypool Life Sciences.

Etchevers, H.C., Amiel, J., and Lyonnet, S. Molecular bases of human neurochristopathies. Advances in Experimental Medicine and Biology: Neural Crest Induction and Differentiation (2006) 589: 213-234.

Fagotto, F., Glück, U., and Gumbiner, B.M. Nuclear localization signal-independent and importin/karyopherin-independent nuclear import of $\beta$-catenin. Current Biology (1998) 8(4): 181-190.

Fiedler et al. Dishevelled interacts with the DIX domain polymerization interface of Axin to interfere with its function in down-regulating $\beta$-catenin. Proceedings of the National Academy of Sciences (2011) 108(5): 1937-1942.

Giles, R.H., van Es, J.H., \& Clevers, H. Caught up in a Wnt storm: Wnt signaling in cancer. Biochimica et Biophysica Acta (BBA) - Reviews on Cancer (2003)1653(1): 1-24.

Grumolato et al. Canonical and noncanonical Wnts use a common mechanism to activate completely unrelated co-receptors. Genes \& Development (2010) 24(22): 2517-2530.

Hattori, M., Osterfield, M., \& Flanagan, J.G. Regulated cleavage of a contact-mediated axon repellent. Science (2000) 289(5483): 1360-1365.

Hart et al. The F-box protein $\beta$-TrCP associates with phosphorylated $\beta$-catenin and regulates its activity in the cell. Current Biology (1999) 9(4): 207-211. 
Hecht et al. The p300/CBP acetyltransferases function as transcriptional coactivators of $\beta$-catenin in vertebrates. The EMBO Journal (2000) 19(8): 1839-1850.

Henderson, B.R. Nuclear-cytoplasmic shuttling of APC regulates $\beta$-catenin subcellular localization and turnover. Nature Cell Biology (2000) 2: 653-660.

Herr, P., Hausmann, G., and Basler, K. Wnt secretion and signaling in human disease. Trends in Molecular Medicine (2012) 8(18): 483-493.

Hikasa, H. and Sokol, S.Y. Wnt signaling in vertebrate axis specification. Cold Spring Harbor Perspectives in Biology (2013) 5: a007955.

Howe, L.R. and Brown, A.M.C. Wnt signaling and breast cancer. Cancer Biology and Therapy (2004) 3(1): 36-41.

$\mathrm{Hu}$ et al. c-Jun $\mathrm{N}$-terminal kinase 1 interacts with and negatively regulates $\mathrm{Wnt} / \mathrm{\beta}$ catenin signaling through GSK3 $\beta$ pathway. Carcinogenesis (2008) 29(12): 23172324.

$\mathrm{Hu}$ et al. GSK3 $\beta$ is involved in JNK2-mediated $\beta$-catenin inhibition. PloS ONE (2009) 4(8): e6640.

Huang, P., Senga, T., and Hamaguchi, M. A novel role of phospho- $\beta$-catenin in microtubule regrowth at centrosome. Oncogene (2007) 26(30): 4357-4371.

Huber et al. Nuclear localization of $\beta$-catenin by interaction with transcription factor LEF1. Mechanisms of Development (1996) 59: 3-10.

Inestrosa, N.C., and Varela-Nallar, L. (2013). Chapter 4: Wnt Signaling Roles on the Structure and Function of the Central Synapses: Involvement in Alzheimer's Disease. In Wislet, S. Trends in Cell Signaling Pathways in Neuronal Fate Decision. InTechOpen. Chapter published March 27, 2013 under CC BY 3.0 license. Available from: http://dx.doi.org/10.5772/54606.

Janda et al. Structural basis of Wnt Recognition by Frizzled. Science (2012)337: 59-64.

Janes, et al. Adam meets Eph: an ADAM substrate recognition module acts as a molecular switch for ephrin cleavage in trans. Cell (2005) 123(2): 291-304.

Jian et al. Smad3-dependent nuclear translocation of $\beta$-catenin is required for TGF- $\beta 1$ induced proliferation of bone marrow-derived adult human mesenchymal stem cell. Genes and Development (2006) 20: 666-674.

Kania, A., and Klein, R. Mechanisms of ephrin-Eph signaling in development, physiology and disease. Nature Reviews Molecular Cell Biology (2016) 17: 240256. Available from: http://dx.doi.org/10.1038/nrm.2015.16. 
Kikuchi et al. New insights into the mechanism of Wnt signaling pathway activation. International Review of Cell and Molecular Biology (2011) 291(21): e71.

Klein, R. Eph/ephrin signaling during development. Development (2012) 139: 41054109.

Krieghoff, E., Behrens, J., and Mayr, B. Nucleo-cytoplasmic distribution of $\beta$-catenin is regulated by retention. Journal of Cell Science (2006) 119(7): 1453-1463.

Kullander, K., \& Klein, R. Mechanisms and functions of Eph and ephrin signaling. Nature Reviews Molecular Cell Biology (2002) 3(7): 475-486.

Latres, E., Chiaur, D.S., and Pagano, M. The human $\mathrm{F}$ box protein $\beta$-Trcp associates with the Cul1/Skp1 complex and regulates the stability of $\beta$-catenin. Oncogene (1999) 18(4): 849-854.

Lau, A.W., Fukushima, H., and Wei, W. The Fbw7 and Beta-TRCP E3 ubiquitin ligases and their roles in tumorigenesis. Frontiers in Bioscience (2012) 17: 2197- 2212.

Le Douarin, N., and Kalcheim, C. The Neural Crest. (1999) 36. Cambridge University Press.

Lento et al. Wnt signaling in normal and malignant hematopoiesis. Cold Spring Harbor Perspectives in Biology (2013) 5: a008011.

Li et al. Transforming growth factor- $\beta$ stimulates cyclin $D_{1}$ expression through activation of $\beta$-catenin signaling in chondrocytes. Journal of Biological Chemistry (2006) 281(30): 21296-21304.

Li et al. CBP/p300 are bimodal regulators of Wnt signaling. The EMBO Journal (2007) 26(9), 2284-2294.

Li et al. Chibby cooperates with 14-3-3 to regulate $\beta$-catenin subcellular distribution and signaling activity. Journal of Cell Biology (2008) 181(7): 1141-1154.

Li et al. Nuclear-cytoplasmic shuttling of Chibby controls $\beta$-catenin signaling. Molecular Biology of the Cell (2010) 21: 311-322.

Li et al. The cytoplasmic domain of MUC1 induces hyperplasia in the mammary gland and correlates with nuclear accumulation of $\beta$-catenin. PLOS ONE (2011) 6(4): e19102.

Li et al. Nucleo-cytoplasmic shuttling of PAK4 modulates $\beta$-catenin intracellular translocation and signaling. Biochemica et Biophysica Acta (2012a) 1823: 465475. 
Li et al. Wnt signaling through inhibition of $\beta$-catenin degradation in an intact Axin1 complex. Cell (2012b) 149(6): 1245-1256.

$\mathrm{Li}, \mathrm{Y} .$, and Bu, G. LRP5/6 in Wnt signaling and tumorigenesis. Future Oncology (2005) 1(5): 673-681.

Liao et al. Jun $\mathrm{NH} 2$-terminal kinase (JNK) prevents nuclear $\beta$-catenin accumulation and regulates axis formation in Xenopus embryos. PNAS (2006) 103(44): 1631316318.

Lim, X., and Nusse, R. Wnt signaling in skin development, homeostasis, and disease. Cold Spring Harbor Perspectives in Biology (2013) 5: a008029.

Liu et al. Control of $\beta$-catenin phosphorylation/degradation by a dual-kinase mechanism. Cell (2002) 108: 837-847.

Logan, C.Y., and Nusse, R. The Wnt signaling pathway in development and disease. Annual Reviews of Cell and Developmental Biology (2004) 20: 781-810.

Lorenowicz, M.J., and Korswagen, H.C. Sailing with the Wnt: Charting the Wnt processing and secretion route. Experimental Cell Research (2009) 315(16): 2683-2689.

Maher, et al. $\beta$-Catenin phosphorylated at serine 45 is spatially uncoupled from $\beta$ catenin phosphorylated in the GSK3 domain: implications for signaling. PloS ONE (2010) 5(4): e10184.

Marston, D.J., Dickinson, S., and Nobes, C.D. Rac-dependent trans-endocytosis of ephrinBs regulates Eph-ephrin contact repulsion. Nature Cell Biology (2003) 5(10): 879-888.

Mikels, A.J., and Nusse, R. Wnts as ligands: processing, secretion and reception. Oncogene (2006) 25(57): 7461-7468.

Molenaar et al. XTcf-3 Transcription factor mediates $\beta$-catenin-induced axis formation in Xenopus embryos. Cell (1996) 86: 391-399.

Morgan et al. Factors affecting the nuclear localization of $\beta$-catenin in normal and malignant tissue. Journal of Cellular Biochemistry (2014) 115: 1351-1361.

Mosimann, C., Hausmann, G., and Basler, K. $\beta$-catenin hits chromatin: regulation of Wnt target gene activation. Nature Reviews Molecular Cell Biology (2009) 10(4): 276-286.

Mulholland et al. The androgen receptor can promote $\beta$-catenin nuclear translocation independently of adenomatous polyposis coli. Journal of Biological Chemistry (2002) 277(20): 17933-197943. 
Neufeld et al. Adenomatous polyposis coli protein contains two nuclear export signals and shuttles between the nucleus and cytoplasm. PNAS (2000a) 97: 1208512090.

Neufeld et al. APC-mediated down-regulation of $\beta$-catenin activity involves nuclear sequestration and nuclear export. EMBO Reports (2000b) 1: 519-523

Nguyen et al. WNT/TCF signaling through LEF1 and HOXB9 mediates lung adenocarcinoma metastasis. Cell (2009) 138: 51-62.

Niehrs, C. The complex world of WNT receptor signaling. Nature Reviews Molecular Cell Biology (2012) 13(12): 767-779.

Palsgaard et al. Cross-talk between Insulin and Wnt signaling in preadipocytes - Role of Wnt co-receptor low density lipoprotein receptor-related protein-5 (LRP5). The Journal of Biological Chemistry (2012) 287(15): 12016-12026.

Pasquale, E. Eph-Ephrin bidirectional signaling in physiology and disease. Cell (2008) 133: 38-52.

Pasquale, E. Eph receptors and ephrins in cancer: bidirectional signaling and beyond. Nature Reviews (2010) 10: 165-180.

Patthey, C., Gunhaga, L., and Edlund, T. Early development of the central and peripheral nervous systems is coordinated by Wnt and BMP signals. PLOS ONE (2008) 3(2): e1625.

Pawlowski et al. Liganded androgen receptor interaction with $\beta$-catenin: Nuclear colocalization and modulation of transcriptional activity in neuronal cells. Journal of Biological Chemistry (2002) 277(23): 20702-20710.

Peng et al. V3D enables real-time 3D visualization and quantitative analysis of largescale biological image data sets. Nature Biotechnology (2010) 28(4): 348-353.

Peng et al. Virtual finger boosts three-dimensional imaging and microsurgery as well as terabyte volume image visualization and analysis. Nature Communications (2014) 5(4342).

Peradziryi, H., Tolwinski, N.S., and Borchers, A. The many roles of PTK7: a versatile regulator of cell-cell communication. Archives of Biochemistry and Biophysics (2012) 524(1): 71-76.

Peterson, C.P. and Reddien, P.W. Wnt signaling and the polarity of the primary body axis. Cell (2009) 139: 1056-1068. 
Pitulescu, M. E., \& Adams, R. H. Eph/ephrin molecules-a hub for signaling and endocytosis. Genes \& Development (2010) 24(22): 2480-2492.

Polakis, P. Wnt signaling in cancer. Cold Spring Harbor Perspectives in Biology (2012) 4: a0080524.

Port, F., and Basler, K. Wnt Trafficking: New insights into maturation, secretion, and spreading. Traffic (2010) 11: 1265-1271.

Regard, J.B. et al. Wnt signaling in bone development and disease: Making stronger bone with Wnts. Cold Spring Harbor Perspectives in Biology (2012) 4: a007997.

Reya, T., and Clevers, H. Wnt signaling in stem cells and cancer. Nature (2005) 434: 843-850.

Rheinbay et al. An aberrant transcription factor network essential for Wnt signaling and stem cell maintenance in glioblastoma. Cell Reports (2013) 3(5): 1567-1579.

Roose et. Al. The Xenopus Wnt effector XTcf-3 interacts with Groucho-related transcriptional repressors. Nature (1998) 395(6702): 608-612.

Rosin-Arbesfeld et al. Nuclear export of the APC tumour suppressor controls $\beta$-catenin function in transcription. The EMBO Journal (2003) 22(5): 1101-1113.

Salinas, P.C. Wnt signaling in the vertebrate central nervous system: From axon guidance to synaptic function. Cold Spring Harbor Perspectives in Biology (2012) 4: a008003.

Schambony, A., and Wedlich, D. Wnt Signaling and Cell Migration. Madame Curie Bioscience Database [Internet] (2000). Landes Bioscience.

Schepers, A. and Clevers, H. Wnt signaling, stem cells, and cancer of the gastrointestinal tract. Cold Spring Harbor Perspectives in Biology (2012) 4: a007989.

Schindelin et al. Fiji: an open-source platform for biological-image analysis. Nature Methods (2012) 9(7): 676-682.

Schwab et al. Pygo1 and Pygo2 roles in Wnt signaling in mammalian kidney development. BMC Biology (2007) 5(1): 15.

Schwarz-Romond et. Al. The DIX domain of Dishevelled confers Wnt signaling by dynamic polymerization. Nature Structural \& Molecular Biology (2007) 14(6): 484-492. 
Sharma et al. Specific armadillo repeat sequences facilitate $\beta$-catenin nuclear transport in live cells via direct binding to nucleoporins Nup62, Nup153, and RanBP2/Nup358. Journal of Biological Chemistry (2012) 287(2): 819-831.

Simcha et al. Differential nuclear translocation and transactivation potential of $\beta$-catenin and plakoglobin. Journal of Cellular Biology (1998) 141(6): 1433-1448.

Stamos, J.L., and Weis, W.I. The $\beta$-catenin destruction complex. Cold Spring Harbor Perspectives in Biology (2013) 5(1): a007898.

Stein et al. Nck recruitment to Eph receptor, EphB1/ELK, couples ligand activation to cJun kinase. Journal of Biological Chemistry (1998) 273(3): 1303-1308.

Su et al. APC is essential for targeting phosphorylated $\beta$-catenin to the $\mathrm{SCF}^{\beta-\operatorname{TrCP}}$ ubiquitin ligase. Molecular Cell (2008) 32: 652-661.

Takada et al. Monounsaturated fatty acid modification of Wnt protein: Its role in Wnt secretion. Developmental Cell (2006) 11(6): 791-801.

Takemaru, K.I., and Moon, R.T. The transcriptional coactivator CBP interacts with $\beta$ catenin to activate gene expression. The Journal of Cell Biology (2000) 149(2): 249-254.

Tan et al. Analysis of Wnt signaling $\beta$-catenin spatial dynamics in HEK293T cells. BMC Systems Biology (2014) 8: 44.

Teo, J.L., and Kahn, M. The Wnt signaling pathway in cellular proliferation and differentiation: A tale of two coactivators. Advanced Drug Delivery Reviews (2010) 62: 1149-1155.

Thyssen et al. LZTS2 is a novel $\beta$-catenin-interacting protein and regulates the nuclear export of $\beta$-catenin. Molecular and Cellular Biology (2006) 26(23): 8857-8867.

Valenta, T., Hausmann, G., and Basler, K. The many faces and functions of $\beta$-catenin. The EMBO Journal (2012) 31: 2714-2736.

van Amerongen, R., and Nusse, R. Towards an integrated view of Wnt signaling in development. Development (2009) 136: 3205-3214.

van Amerongen, R. Alternative Wnt pathways and receptors. Cold Spring Harbor Perspectives in Biology (2012) 4: a007914.

Veerle et al. The Wnt/frizzled pathway in cardiovascular development and disease: Friend or foe? European Journal of Pharmacology (2008) 585: 338-345. 
Verheyen, E.M. and Gottardi, C.J. Regulation of Wnt/B-catenin signaling by protein kinases. Developmental Dynamics (2010) 239(1): 34-44.

von Maltzahn et al. Wnt signaling in myogenesis. Trends in Cell Biology (2012) 22(11): 602-609.

Walter et al. Visualization of image data from cells to organisms. Nature Methods (2010). 7: S26-S41.

Wang et al. Nucleo-cytoplasmic shuttling of human Kank protein accompanies intracellular translocation of $\beta$-catenin. Journal of Cell Science (2006) 119(19): 4002-4010.

Wang et al. Regulation of the phosphorylation and nuclear import and export of $\beta$ catenin by APC and its cancer-related truncated form. Journal of Cell Science (2014) 127: 1647-1659.

Wei et al. ADAM13 induces cranial neural crest by cleaving class B Ephrins and regulating Wnt signaling. Developmental Cell (2010) 19: 345-52. Available from: http://dx.doi.org/10.1016/j.devcel.2010.07.012.

Wen et al. Nuclear association of the cytoplasmic tail of MUC1 and $\beta$-catenin. Journal of Biological Chemistry (2003) 278(39): 38029-38039.

Wiechens, N., and Fagotto, F. CRM1- and Ran-independent nuclear export of $\beta$ catenin. Current Biology (2001) 11: 18-27.

Wiechens et al. Nucleo-cytoplasmic shuttling of Axin, a negative regulator of the Wnt- $\beta$ catenin pathway. Journal of Biological Chemistry (2004) 279(7): 5263-5267.

Wislet, S. Trends in Cell Signaling Pathways in Neuronal Fate Decision. InTechOpen (2013) Chapters published March 27, 2013 under CC BY 3.0 license. Available from: http://dx.doi.org/10.5772/3445.

Wu et al. Rac1 activation and subsequent $\beta$-catenin phosphorylation controls nuclear localization of $\beta$-catenin during canonical Wnt signaling. Cell (2008) 133: 340353.

Wu, J., Yang, J., and Klein, P.S. Neural crest induction by the canonical Wnt pathway can be dissociated from anterior-posterior neural patterning in Xenopus. Developmental Biology (2005) 279: 220-232.

Wybenga-Groot, et al. Structural basis for autoinhibition of the Ephb2 receptor tyrosine kinase by the unphosphorylated juxtamembrane region. Cell (2001) 106(6): 745757. 
Xing et al. Crystal structure of full-length beta-catenin. Structure (2008) 16(3): 478-487.

Xu, N.J., \& Henkemeyer, M. Ephrin reverse signaling in axon guidance and synaptogenesis. Seminars in Cell \& Developmental Biology (2002) 23(1): p. 5864.

Yokoya et al. $\beta$-catenin can be transported into the nucleus in a Ran-unassisted manner. Molecular Biology of the Cell (1999) 10: 1119-1131.

Zeng et al. A dual-kinase mechanism for Wnt co-receptor phosphorylation and activation. Nature (2005) 438(7069): 873-877.

Zhang et al. Inhibitory Phosphorylation of Glycogen Synthase Kinase-3 (GSK-3) in Response to Lithium. The Journal of Biological Chemistry (2003) 278(35): 3306733077.

Zhang et al. Smad3 prevents $\beta$-catenin degradation and facilitates $\beta$-catenin nuclear translocation in chondrocytes. Journal of Biological Chemistry (2010) 285(12): 8703-8710.

Zhang et al. FoxM1 promotes $\beta$-catenin nuclear localization and controls Wnt targetgene expression and glioma tumorigenesis. Cancer Cell (2011) 20: 427-442.

Zimmer, et al. EphB-ephrinB bi-directional endocytosis terminates adhesion allowing contact mediated repulsion. Nature Cell Biology (2003) 5(10): 869-878. 